\title{
Article \\ Spatiotemporal Rainfall Variability and Drought Assessment during Past Five Decades in South Korea Using SPI and SPEI
}

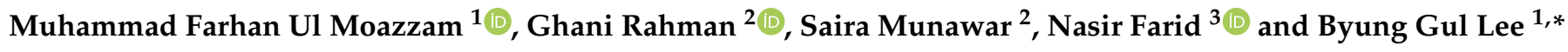 \\ 1 Department of Civil Engineering, College of Ocean Science, Jeju National University, 102 Jejudaehakro, \\ Jeju 63243, Korea; farhan.moazzam@gmail.com \\ 2 Department of Geography, University of Gujrat, Gujrat 50700, Pakistan; ghanigeo@gmail.com (G.R.); \\ saira.munawar@uog.edu.pk (S.M.) \\ 3 Department of Geography, University of Peshawar, Peshawar 25001, Pakistan; nasirfaridk@gmail.com \\ * Correspondence: leebg@jejunu.ac.kr
}

check for

updates

Citation: Moazzam, M.F.U.; Rahman,

G.; Munawar, S.; Farid, N.; Lee, B.G. Spatiotemporal Rainfall Variability and Drought Assessment during Past Five Decades in South Korea Using SPI and SPEI. Atmosphere 2022, 13, 292. https://doi.org/10.3390/ atmos13020292

Academic Editors: Xieyao Ma, Xiefei Zhi, Kamran Azam and Irfan Ullah

Received: 21 January 2022 Accepted: 7 February 2022

Published: 9 February 2022

Publisher's Note: MDPI stays neutral with regard to jurisdictional claims in published maps and institutional affiliations.

Copyright: () 2022 by the authors. Licensee MDPI, Basel, Switzerland. This article is an open access article distributed under the terms and conditions of the Creative Commons Attribution (CC BY) license (https:// creativecommons.org/licenses/by/ $4.0 /)$.

\begin{abstract}
About $41 \%$ of the earth is drought-affected, which has impacted nearly 2 billion people, and it is expected that more than $90 \%$ of terrestrial areas will be degraded by 2050 . To evade and mitigate the harmful impacts of drought, it is necessary to study the rainfall variability and assess the drought trend at a global and regional level. This study utilized 70 meteorological stations in South Korea to evaluate the rainfall variability, drought, and its trend during the past five decades using the standardized precipitation evapotranspiration index (SPEI) and the standardized precipitation index (SPI). Rainfall data normality was assessed with mean, standard deviation, skewness, and kurtosis. The highest amount of rainfall was observed in the months of June, July, and August. The SPI and SPEI 12-month results revealed that 1982, 1988, 2008, 2015, and 2017 were dry years throughout the country, while from 2013 to 2017 mixed drought events were observed for the 6-month time series. The Mann-Kendall trend test was applied to the 1- and 12-month time series, and the results revealed that the months of January, March, April, May, June, and August had a significant negative trend, which means drought is increasing in these months, while the months of September, October, and December had a significant positive trend, which means wetter conditions prevailed in these months during the study period. It was observed in the 12-month time series that only two met stations had a significant negative trend, while only one had a significant positive trend. It was found that January and March were the driest months, and October was the wettest month. The detected drought events in this research are consistent with ENSO events. We have observed differences in drought characteristics (duration and frequency) for both indices. Climatic data revealed that South Korea has faced drought conditions (rainfall deficit) due to a shortened monsoon season. This study can provide guidance on water management strategies under the changing pattern of drought in South Korea.
\end{abstract}

Keywords: drought characteristics; SPI; SPEI; Mann-Kendall Test

\section{Introduction}

Drought is one of the most frequently occurring and severe hydrometeorological phenomena, resulting from a decrease in rainfall from normal conditions, causing water scarcity for various water-dependent activities $[1,2]$. Drought is a costly and destructive hazard with an extensive impact on the environment, socioeconomics, and populations around the globe [3,4]. Due to the shift in climatological patterns (rainfall and temperature), droughts are occurring more frequently [5,6]. Dai, (2013) [7] has projected that the intensity and frequency of drought will increase in the 21st century. Drought is a slow onset event with effects can be seen even after the end of the event, which makes it difficult to identify the start and end of it [8-10]. Drought is characterized into four types, deficit of rainfall from its average, initiating meteorological drought $[3,11]$, which leads to a dearth of streamflow 
and causes a decline in water in reservoirs, named as hydrological drought [12]. Thus, water shortfall for agricultural needs lead to agricultural drought and less soil moisture affect crops and their yield, causing starvation, which can ultimately trigger socioeconomic drought $[9,13]$. Shortage of rainfall is the main cause of drought, but other factors of climate can increase its severity, i.e., high temperature, wind, and humidity $[8,10,14,15]$. Drought occurs frequently around the world for months, a season, or even years, but drought characteristics vary in terms of climate zones [12]. Drought-affected areas take a long time to recover after a long period of drought [16]. Therefore, it is very necessary to study drought to reduce its associated risks $[17,18]$.

Global warming-influenced climate change in South Korea has adverse effects on agriculture and water resources $[19,20]$ that lead to severe flooding and droughts $[21,22]$. Korea experienced extreme droughts on a 5-year return period, with some historical events occurring in 1967-1968, 1976-1977, 1981-1982, 1994-1995, and, recently, 2014-2015 [23]. An increasing temperature profile, with below average precipitation, leads to a soil moisture deficit that results in drought risk over arid and semi-arid regions. Wu et al., (2018) [24] observed that the deficit of soil moisture due to global warming in the spring and summer seasons leads to drought [7,17]. Udddin et al., (2020) [25] investigated the drought pattern in Bangladesh using SPEI and SPI and revealed that SPEI had better performance, because PET had a positive influence on identifying the drought. Rahman et al., (2018) [11] used SPI for the evaluation of drought and found a dry period from 1984-1989 and 1998-2002 in the Khyber Pakhtunkhwa Province of Pakistan. Azam et al., (2018a) [26] studied the spatiotemporal pattern of precipitation and drought in South Korea using SPI and various trend tests. The authors noticed a significant trend in precipitation for different seasons regardless of annual precipitation. The same authors also observed a significant increase in drought severity at the northeast coast with frequent droughts in all seasons except in the summer season. Jang (2018) [27] analyzed meteorological drought using SPI and RDI with the representative concentration pathway (RCP) 8.5 scenario (2011-2100) for Korea. The author observed the wet conditions nationwide in SPI 3, SPI 6, and SPI 12-month timescales, but the RDI showed contradictory results to the SPI, in RDI 3, RDI 6, and RDI 12-month time scales Korea faced dry conditions. It was also observed by the author that the country will face extreme drought intensity after 2070 due to the rise in temperature. Kwon et al., (2019) [28] studied drought using SPI and SSI (standardized soil moisture index) with precipitation and soil moisture data and examined that SSI has fewer drought events, but their duration was longer compared to SPI. The authors suggested that SSI was efficient for illustrating drought persistence, but SPI was appropriate for onset of drought. Various studies have been conducted on drought assessment for South Korea using different indices; however, in the previous studies we have seen a lack of spatiotemporal drought for both the long and short term based on SPI and SPEI. It was also noted that none of the studies compared the SPI (based on precipitation) and SPEI (based on precipitation and temperature) index for drought in South Korea; only Sung et al., (2020) [29] compared it for future drought projections using CMIP5 data. Therefore, to fill this gap, we investigated the spatiotemporal meteorological drought thoroughly on 1-, 6-, and 12-month time scales to understand the pattern and characteristics of drought in South Korea.

More than $85 \%$ of global damage occurs due to extreme hydrometeorological events and drought contributes a large part to this. In the first decade of the 21st century, the world has lost USD 722 billion with 2300 million people affected due to drought [30,31]. Drought has a huge impact on agriculture and the environment, which can influence socioeconomic development [10,32,33] because soil degradation leads to desertification, famine, and poverty [12]. It is predicted that the global air temperature will rise by $0.78-1.5^{\circ} \mathrm{C}[34]$, which will change rainfall patterns, eventually increasing the occurrence and severity of drought [12]. This changing climate can pose serious threats to water resources, environmental sustainability, and socioeconomic development $[35,36]$. Thus, the monitoring of drought, its characteristics, and early warning is significant to reducing its impacts on a regional and global scale. To study drought, meteorological scientists have 
developed various drought indices to measure drought severity, i.e., the standardized precipitation index (SPI) [37], the standardized precipitation evapotranspiration index (SPEI) [38], the Palmer drought severity index (PDSI) [39], the reconnaissance drought index (RDI) [40], and the crop moisture index (CMI) [41]. SPI requires only precipitation data, while RDI, PDSI, and SPEI require additional potential evapotranspiration (PET) data to compute drought. Thus, the key aim of this research is to study meteorological drought and its characteristics using the SPI and SPEI drought indexes and to assess the trend of drought using the Mann-Kendall test (MK test). The efforts made through this study will significantly help the authorities to mitigate the impacts of meteorological drought at an early stage before the situation worsens and leads to hydrological and agricultural drought conditions.

\section{Study Area and Data}

South Korea is a part of East Asia located between Japan and China at $33-43^{\circ} \mathrm{N}$ latitude and $124-131^{\circ}$ E longitude, and the total area of the country is $100,210 \mathrm{~km}^{2}$. Figure 1 shows the administrative boundaries, elevation, and meteorological stations (70) used in this study. South Korea experiences four different seasons: winter (Dec-Feb), spring (March-May), summer (June-August), and autumn (September-November) [42,43]. South Korea lies in the Asian monsoon region, which experiences wet summers with more than 50\% of annual rainfall with heavy rain and typhoons [27]. Many parts of South Korea receive more than $1200 \mathrm{~mm}$ of annual rainfall, which is greater than the global average rainfall $[28,44]$, but some parts receive less than $1000 \mathrm{~mm}$ rainfall and have a shortage of rainfall in the crop growing season (April-October); thus, the country experiences droughts [45]. Due to topographic variability and mountainous terrain the climate of South Korea has complex spatial variations. The average temperature in South Korea ranges between $10-15{ }^{\circ} \mathrm{C}[46,47]$.

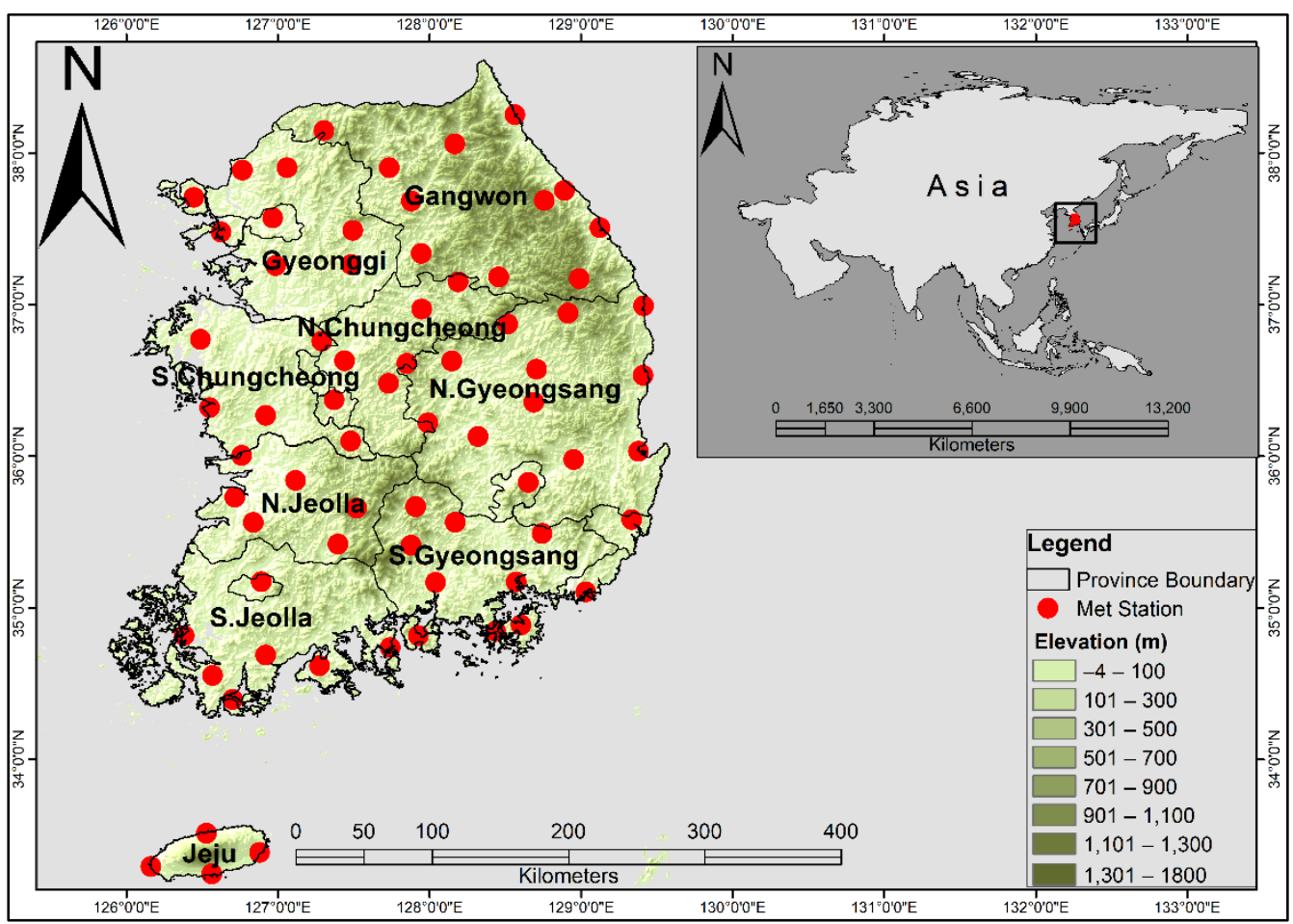

Figure 1. Map of South Korea with elevation and meteorological stations.

\section{Data Collection}

The Korean Meteorological Administration (KMA) has installed more than 70 meteorological stations throughout the country for detailed information on precipitation and temperature. The total annual rainfall and mean monthly, minimum, and maximum tem- 
perature data were acquired from the 70 meteorological stations of the KMA for the period of 1979-2020 covering 42 years (Table 1). The data of meteorological stations were not consistent, as some of the stations were established earlier than others. Therefore, to avoid inconsistency in the analysis, we have chosen 1979 for the beginning of this study. Table 2 shows the geographic location and altitude of all the meteorological stations. To control data quality, the missing data were replaced with average values of the data of nearby meteorological stations [48]. For drought calculations, the SPI and SPEI indices were applied using monthly rainfall data in the SPI calculation and rainfall and temperature data for SPEI calculation in this study. The Mann-Kendall trend test was applied for the calculation of the drought trend in the study region.

Table 1. Sources of the dataset.

\begin{tabular}{cc}
\hline Data Type & Source \\
\hline Precipitation, temperature & Korean Meteorological administration (KMA) \\
Digital elevation model (DEM) & Shuttle Radar Topographic Mission (SRTM) \\
Administrative boundary & Nature Earth \\
\hline
\end{tabular}

Table 2. Detail of Meteorological Stations in the Study Area.

\begin{tabular}{|c|c|c|c|c|c|c|c|c|c|}
\hline ID & Name & Lat & Long & Alt (m) & ID & Name & Lat & Long & Alt (m) \\
\hline 90 & Sokcho & 38.25 & 128.56 & 17.53 & 189 & Seogwipo & 33.24 & 126.56 & 51.86 \\
\hline 95 & Cheorwon & 38.14 & 127.3 & 155.48 & 192 & Pearl & 35.16 & 128.04 & 29.35 \\
\hline 98 & Dongducheon & 37.9 & 127.06 & 115.62 & 201 & Enhance & 37.7 & 126.44 & 47.84 \\
\hline 99 & Paju & 37.88 & 126.76 & 30.59 & 202 & Yangpyeong & 37.48 & 127.49 & 47.26 \\
\hline 100 & Daegwallyeong & 37.68 & 128.75 & 772.43 & 203 & Icheon & 37.26 & 127.48 & 80.09 \\
\hline 101 & Chun Cheon & 37.9 & 127.73 & 75.82 & 211 & inje & 38.05 & 128.16 & 201.78 \\
\hline 105 & Gangneung & 37.75 & 128.89 & 27.12 & 212 & Hongcheon & 37.68 & 127.88 & 140.2 \\
\hline 106 & Donghae & 37.5 & 129.12 & 40.46 & 216 & Taebaek & 37.17 & 128.98 & 714.45 \\
\hline 108 & Seoul & 37.57 & 126.96 & 85.67 & 221 & Jecheon & 37.15 & 128.19 & 264.62 \\
\hline 112 & Incheon & 37.47 & 126.62 & 68.99 & 226 & Boeun & 36.48 & 127.73 & 171.31 \\
\hline 114 & Wonju & 37.33 & 127.94 & 150.11 & 232 & Cheonan & 36.76 & 127.29 & 84.78 \\
\hline 119 & Suwon & 37.25 & 126.98 & 39.81 & 235 & Boryeong & 36.32 & 126.55 & 9.98 \\
\hline 121 & Yeongwol & 37.18 & 128.45 & 240.54 & 236 & Buyeo & 36.27 & 126.92 & 13.42 \\
\hline 127 & Chungju & 36.97 & 127.95 & 114.85 & 238 & Geumsan & 36.1 & 127.48 & 172.69 \\
\hline 129 & Seosan & 36.77 & 126.49 & 25.25 & 243 & Buan & 35.72 & 126.71 & 12.2 \\
\hline 130 & Uljin & 36.99 & 129.41 & 48.98 & 244 & Imsil & 36.61 & 127.85 & 247.04 \\
\hline 131 & Cheongju & 36.63 & 127.44 & 58.7 & 245 & Jeongeup & 35.56 & 126.83 & 68.7 \\
\hline 133 & Daejong & 36.37 & 127.37 & 70.22 & 247 & Namwon & 35.42 & 127.39 & 133.49 \\
\hline 135 & Chupungryung & 36.22 & 127.99 & 244.98 & 248 & Longevity & 35.65 & 127.52 & 406.87 \\
\hline 136 & Andong & 36.57 & 128.7 & 141.26 & 260 & Jangheung & 34.68 & 126.91 & 43.99 \\
\hline 138 & Pohang & 36.03 & 129.38 & 3.94 & 261 & Haenam & 34.55 & 126.56 & 16.36 \\
\hline 140 & Gunsan & 36.005 & 126.76 & 27.85 & 262 & Goheung & 34.61 & 127.27 & 53.12 \\
\hline 143 & Daegu & 35.82 & 128.65 & 53.4 & 271 & Baecon & 36.94 & 128.91 & 324.67 \\
\hline 146 & Jeonju & 35.84 & 127.11 & 60.44 & 272 & Lord & 36.87 & 128.51 & 211.32 \\
\hline 152 & Ulsan & 35.58 & 129.33 & 81.14 & 273 & Mungyeong & 36.62 & 128.14 & 173.01 \\
\hline 155 & Changwon & 35.17 & 128.57 & 34.97 & 277 & Yeongdeok & 36.53 & 129.4 & 40.71 \\
\hline 156 & Gwangju & 35.17 & 126.89 & 70.28 & 278 & Uiseong & 36.35 & 128.68 & 81.44 \\
\hline 159 & Busan & 35.1 & 129.03 & 69.56 & 279 & Gumi & 36.13 & 128.32 & 49.17 \\
\hline 162 & Tongyeong & 34.84 & 128.43 & 31.24 & 281 & Yeongcheon & 35.97 & 128.95 & 96.12 \\
\hline 165 & Mokpo & 34.81 & 126.38 & 44.7 & 284 & Geochang & 35.66 & 127.9 & 228.45 \\
\hline 168 & Yeosu & 34.73 & 127.74 & 65.93 & 285 & Hapcheon & 35.56 & 128.16 & 26.72 \\
\hline 170 & Wando & 34.39 & 126.7 & 35.37 & 288 & Miryang & 35.49 & 128.74 & 8.31 \\
\hline 184 & Jeju & 33.51 & 126.52 & 20.97 & 289 & Sancheong & 35.41 & 127.87 & 138.22 \\
\hline 185 & Gosan & 33.29 & 126.16 & 71.39 & 294 & Geoje & 34.88 & 128.6 & 44.83 \\
\hline 188 & Seongsan & 33.38 & 126.88 & 20.34 & 295 & Namhae & 34.81 & 127.92 & 45.71 \\
\hline
\end{tabular}




\section{Methods}

The detailed methodological framework of this study is shown below in Figure 2. Initially, the daily precipitation and temperature data of 70 meteorological stations were acquired from the Korean Meteorological Administration (KMA) for the period of 19792020 (42 years). The detailed summary of the meteorological stations is presented in Table 2. The daily precipitation and temperature datasets were summed to create the monthly and annual datasets. The standardized normalized homogeneity test (SNHT) was used to find the peaks and outliers in the data [49]. During data quality evaluation, it was found that only $2-3 \%$ of the data were missing which would not have a substantial impact on the results [49]; however, we still replaced the missing data with the average values of the nearby meteorological stations to maintain the quality [48]. Next, we calculated the descriptive statistics in XLSAT Adin of Excel software, the details of which are presented in Table 3. Then, we created the monthly and annual rainfall maps (Figures 3 and 4). We used SPI and SPEI to calculate the drought events on 1-, 6-, and 12-month time scales, which are presented in Figures 5 and 6. The trend of drought was assessed using the Mann-Kendall trend test, and maps were prepared (Figures 7 and 8). Finally, the drought frequency and duration was calculated (Figures 9 and 10).

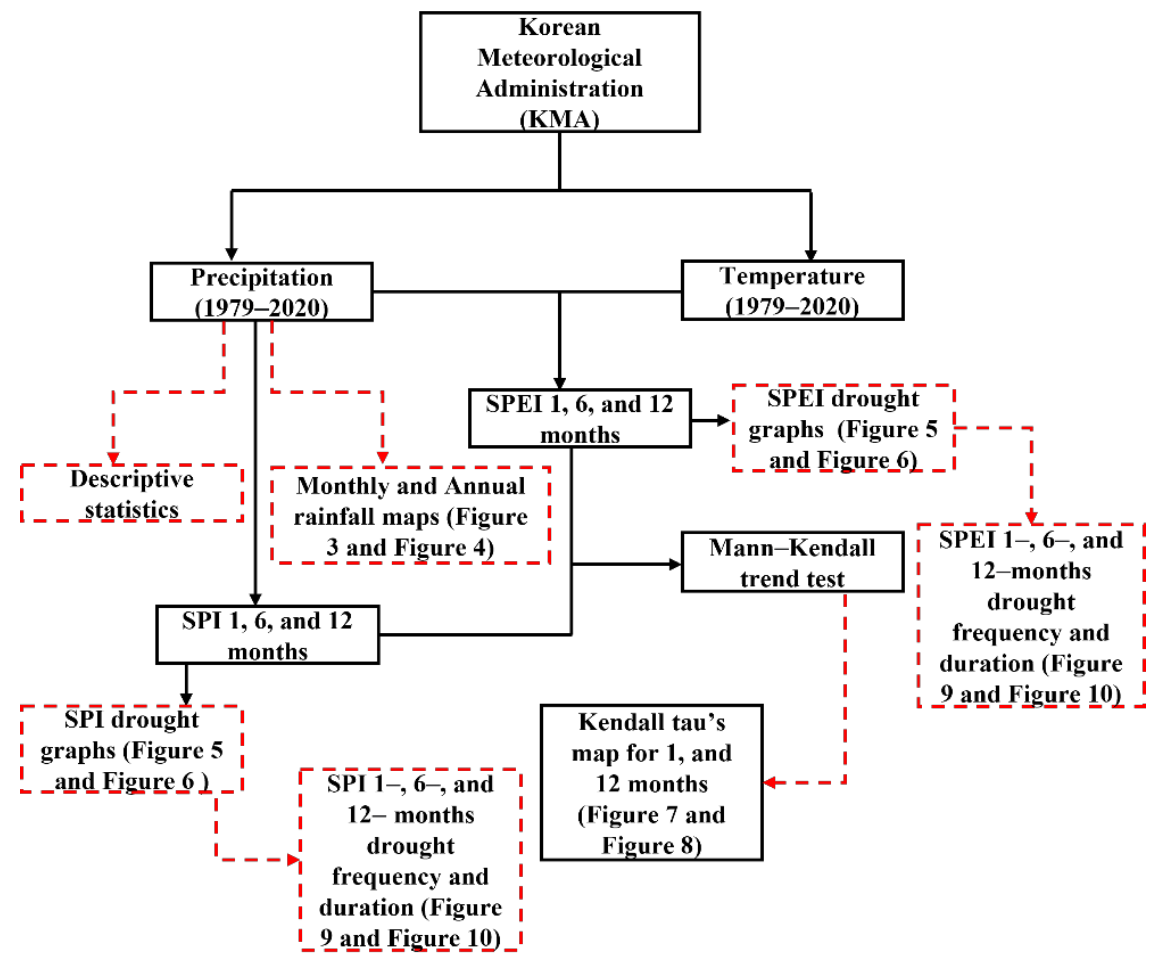

Figure 2. Flowchart of the research. 
Table 3. Descriptive statistics of all meteorological stations in South Korea.

\begin{tabular}{|c|c|c|c|c|c|c|c|c|c|c|c|c|c|}
\hline ID & Min & Max & Mean & STD & $\mathrm{S}$ & $\mathbf{K}$ & ID & Min & Max & Mean & STD & $S$ & $\mathbf{K}$ \\
\hline 90 & 928 & 2086 & 1389.92 & 277.84 & 0.67 & -0.18 & 189 & 1087 & 3244 & 1965.35 & 454.00 & 0.52 & 0.47 \\
\hline 95 & 684 & 2193 & 1365.89 & 313.93 & 0.35 & 0.12 & 192 & 767 & 2193 & 1534.37 & 382.50 & -0.25 & -0.77 \\
\hline 98 & 742 & 2311 & 1446.95 & 373.87 & 0.42 & -0.02 & 201 & 605 & 2365 & 1300.19 & 347.56 & 0.90 & 1.61 \\
\hline 99 & 643 & 2063 & 1295.74 & 358.31 & 0.20 & -0.18 & 202 & 759 & 2255 & 1374.67 & 345.74 & 0.50 & 0.18 \\
\hline 100 & 982 & 2998 & 1684.53 & 496.69 & 0.79 & -0.10 & 203 & 792 & 2313 & 1335.18 & 323.16 & 0.71 & 0.83 \\
\hline 101 & 677 & 2069 & 1328.48 & 310.37 & 0.32 & -0.02 & 211 & 667 & 1779 & 1185.65 & 296.00 & 0.13 & -0.73 \\
\hline 105 & 922 & 2095 & 1436.99 & 308.97 & 0.40 & -0.81 & 212 & 704 & 2375 & 1332.46 & 346.90 & 0.79 & 0.99 \\
\hline 106 & 755 & 1967 & 1264.20 & 325.47 & 0.35 & -0.95 & 216 & 850 & 1973 & 1309.85 & 307.20 & 0.37 & -0.96 \\
\hline 108 & 761 & 2356 & 1399.48 & 377.23 & 0.71 & 0.41 & 221 & 803 & 2231 & 1367.56 & 341.41 & 0.35 & -0.18 \\
\hline 112 & 652 & 2010 & 1195.40 & 287.92 & 0.80 & 0.50 & 226 & 765 & 2085 & 1317.08 & 327.75 & 0.53 & -0.25 \\
\hline 114 & 772 & 2188 & 1311.83 & 309.35 & 0.46 & 0.69 & 232 & 712 & 1846 & 1230.59 & 280.74 & 0.14 & -0.68 \\
\hline 119 & 751 & 2044 & 1305.16 & 278.95 & 0.50 & 0.33 & 235 & 725 & 1898 & 1227.72 & 279.38 & -0.11 & -0.47 \\
\hline 121 & 676 & 2086 & 1205.11 & 310.28 & 0.63 & 0.80 & 236 & 753 & 2138 & 1345.63 & 323.25 & 0.39 & -0.21 \\
\hline 127 & 732 & 2073 & 1213.19 & 298.27 & 0.60 & 0.33 & 238 & 750 & 1827 & 1292.86 & 284.72 & -0.07 & -0.66 \\
\hline 129 & 686 & 2142 & 1259.01 & 313.18 & 0.53 & 0.09 & 243 & 706 & 2074 & 1251.90 & 288.93 & 0.47 & 0.33 \\
\hline 130 & 623 & 1790 & 1138.62 & 291.41 & 0.34 & -0.80 & 244 & 684 & 1974 & 1362.88 & 317.22 & -0.15 & -0.51 \\
\hline 131 & 757 & 1806 & 1241.66 & 267.21 & -0.05 & -0.85 & 245 & 768 & 1917 & 1315.76 & 284.15 & 0.10 & -0.60 \\
\hline 133 & 823 & 2070 & 1358.78 & 316.05 & 0.22 & -0.73 & 247 & 565 & 2050 & 1363.65 & 347.93 & -0.17 & -0.36 \\
\hline 135 & 762 & 1835 & 1189.14 & 253.42 & 0.20 & -0.39 & 248 & 743 & 2208 & 1480.66 & 355.39 & -0.03 & -0.35 \\
\hline 136 & 115 & 1579 & 1025.60 & 260.54 & -0.82 & 2.31 & 260 & 830 & 2357 & 1498.68 & 352.08 & -0.09 & -0.48 \\
\hline 138 & 600 & 2098 & 1160.11 & 315.86 & 0.85 & 0.96 & 261 & 725 & 2108 & 1320.55 & 302.71 & 0.12 & -0.23 \\
\hline 140 & 729 & 1769 & 1239.51 & 288.74 & 0.13 & -0.92 & 262 & 818 & 2485 & 1491.28 & 350.64 & 0.21 & 0.22 \\
\hline 143 & 568 & 1750 & 1075.55 & 245.22 & 0.08 & 0.07 & 271 & 589 & 1736 & 1178.90 & 260.89 & 0.21 & -0.06 \\
\hline 146 & 707 & 1860 & 1301.35 & 278.33 & -0.16 & -0.61 & 272 & 668 & 2019 & 1290.27 & 294.30 & 0.23 & -0.14 \\
\hline 152 & 671 & 2059 & 1286.35 & 320.21 & 0.36 & -0.29 & 273 & 744 & 1963 & 1268.31 & 289.22 & 0.23 & -0.42 \\
\hline 155 & 814 & 2897 & 1515.87 & 419.42 & 0.66 & 1.68 & 277 & 558 & 1841 & 1078.89 & 263.70 & 0.57 & 0.28 \\
\hline 156 & 764 & 2027 & 1388.14 & 338.21 & 0.10 & -0.45 & 278 & 505 & 1697 & 1004.71 & 251.50 & 0.46 & 0.20 \\
\hline 159 & 902 & 2397 & 1555.55 & 397.20 & 0.43 & -0.70 & 279 & 650 & 1750 & 1085.49 & 269.28 & 0.22 & -0.52 \\
\hline 162 & 793 & 2555 & 1501.14 & 368.23 & 0.53 & 0.30 & 281 & 561 & 1724 & 1058.60 & 238.61 & 0.30 & -0.01 \\
\hline 165 & 613 & 1737 & 1175.11 & 275.01 & -0.11 & -0.53 & 284 & 616 & 1958 & 1306.24 & 344.83 & -0.04 & -0.76 \\
\hline 168 & 863 & 2451 & 1468.08 & 332.82 & 0.61 & 0.59 & 285 & 628 & 1863 & 1312.49 & 338.31 & -0.35 & -0.71 \\
\hline 170 & 841 & 2646 & 1543.40 & 376.98 & 0.36 & 0.44 & 288 & 558 & 1880 & 1242.42 & 311.15 & -0.19 & -0.58 \\
\hline 184 & 773 & 2526 & 1503.36 & 415.52 & 0.42 & 0.05 & 289 & 757 & 2493 & 1572.71 & 418.75 & -0.15 & -0.57 \\
\hline 185 & 697 & 1875 & 1165.71 & 270.05 & 0.36 & -0.14 & 294 & 1136 & 3397 & 1893.91 & 525.68 & 0.81 & 0.28 \\
\hline 188 & 1255 & 3194 & 1999.48 & 404.08 & 0.38 & 0.50 & 295 & 1081 & 2844 & 1885.39 & 444.52 & 0.05 & -0.52 \\
\hline
\end{tabular}




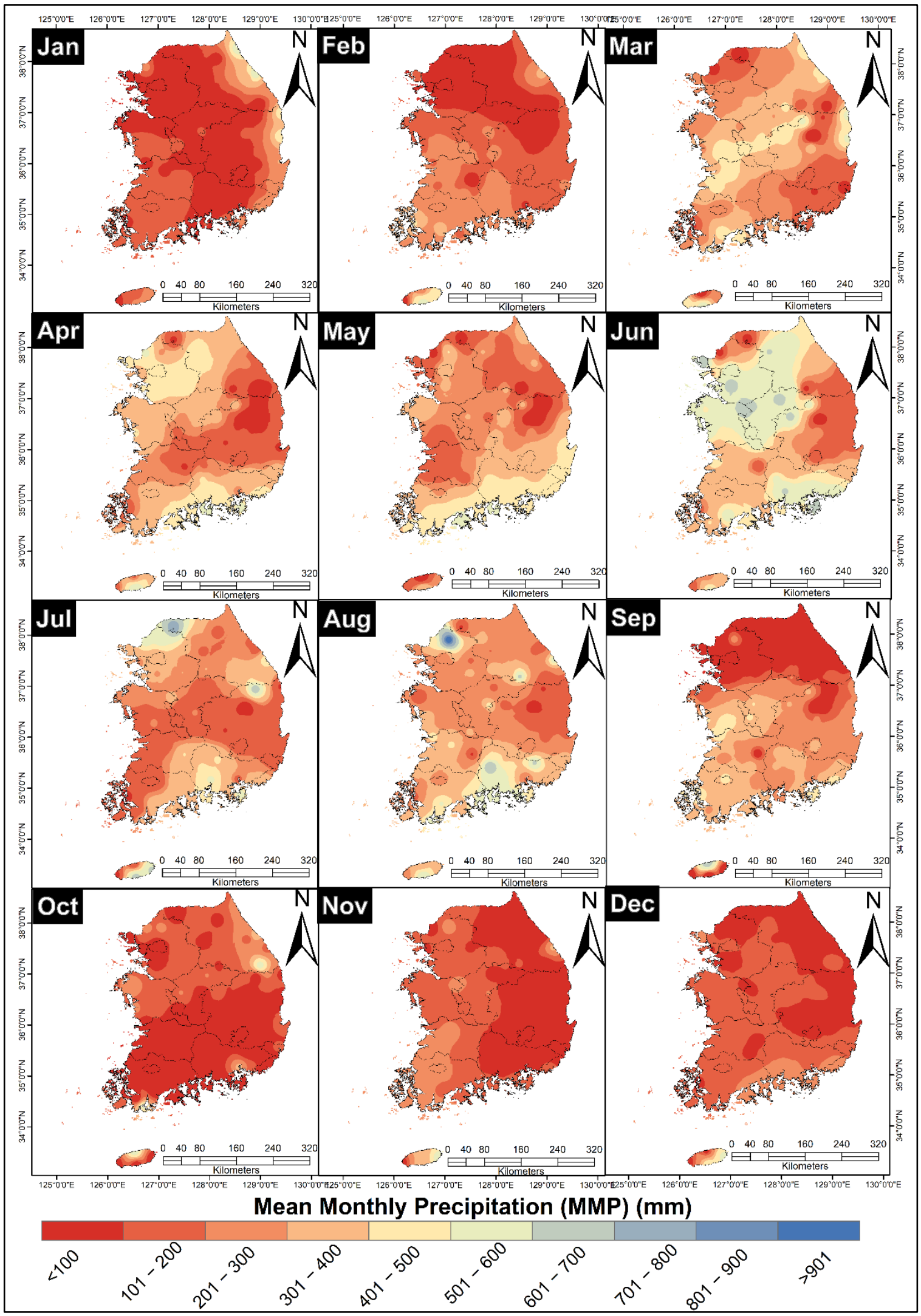

Figure 3. Spatial distribution of mean monthly rainfall in South Korea. 


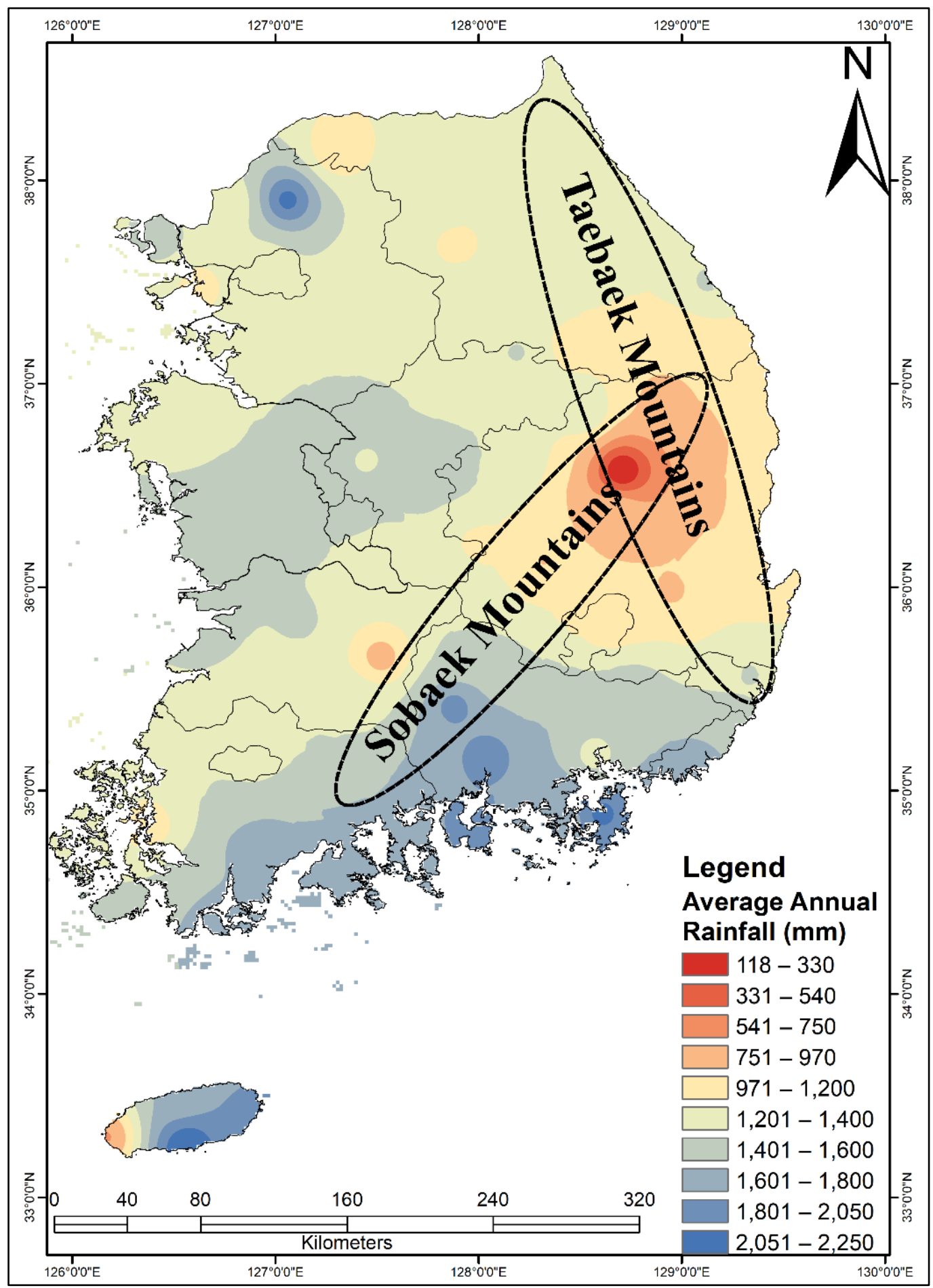

Figure 4. Mean annual rainfall in South Korea (Encircled parts are the two mountain ranges in South Korea). 


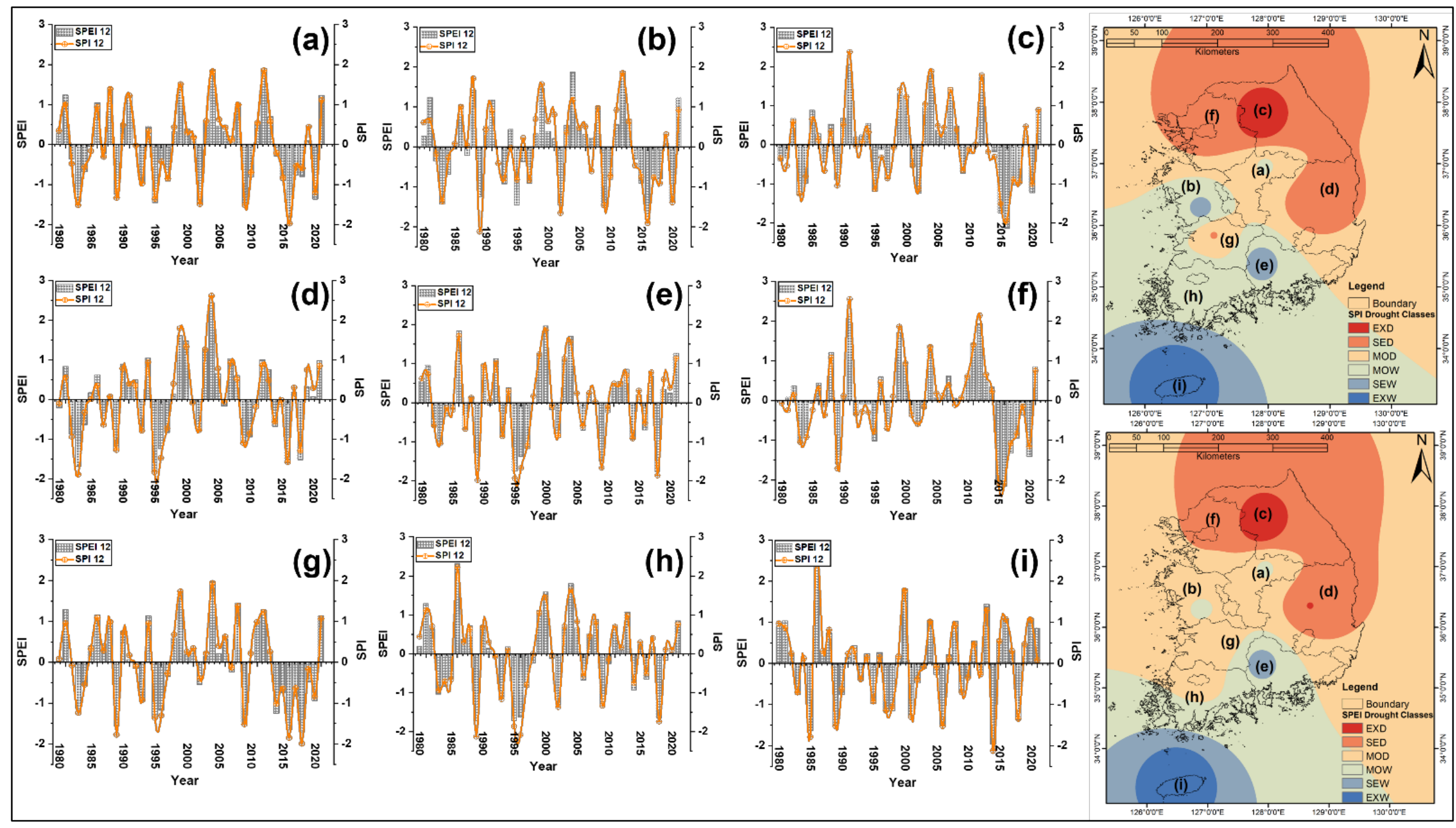

Figure 5. SPEI and SPI 12 (a) North Chungcheong, (b) South Chungcheong, (c) Gangwon, (d) North Gyeongsang, (e) South Gyeongsang, (f) Gyeonggi, (g) North Jeolla, (h) South Jeolla, and (i) Jeju. EXD: Extreme Drought, SED: Severe drought, MOD: Moderate drought, EXW: Extreme wet, SEW: Severe wet, and MOW: Moderate wet. 

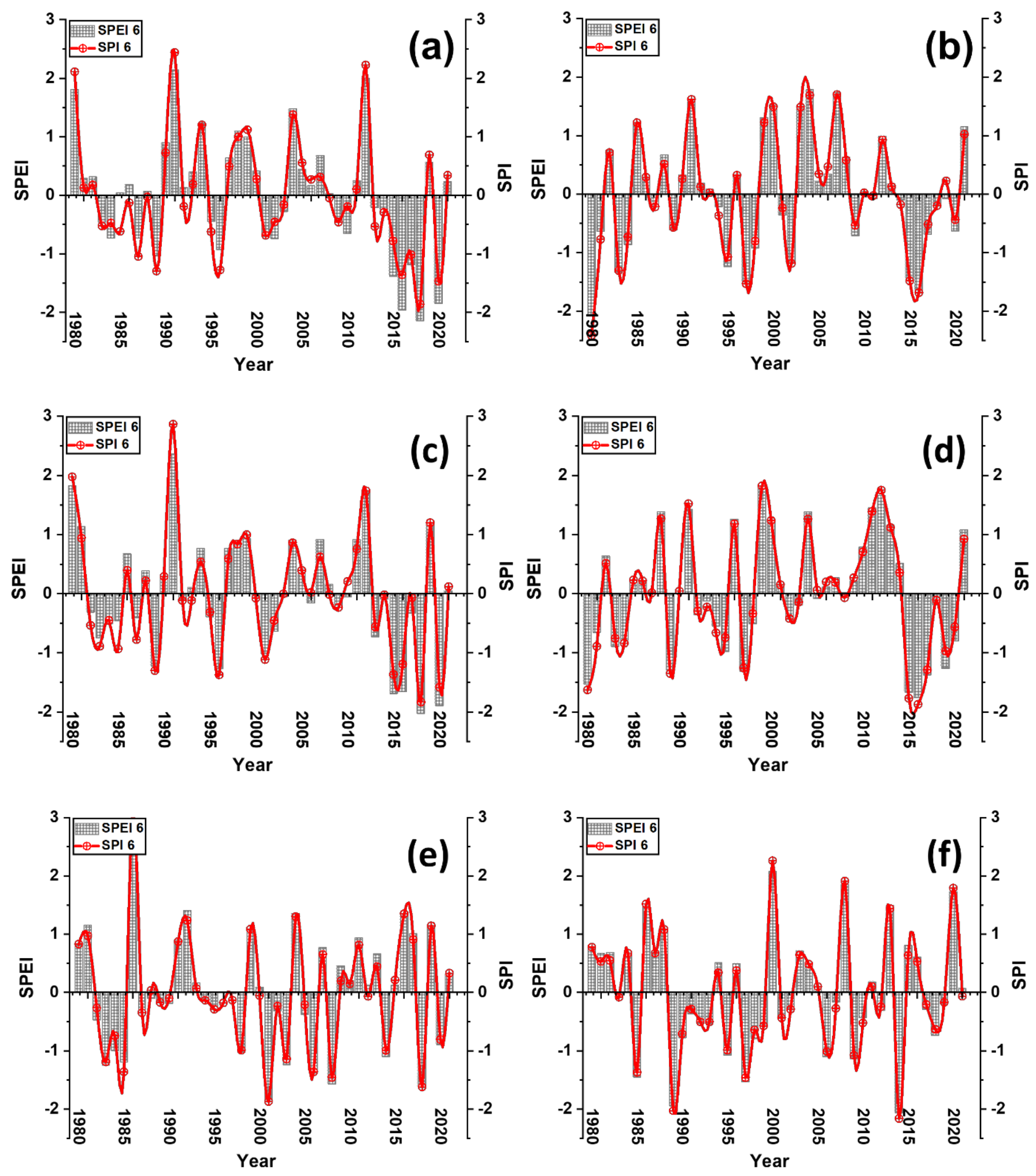

Figure 6. Cont. 

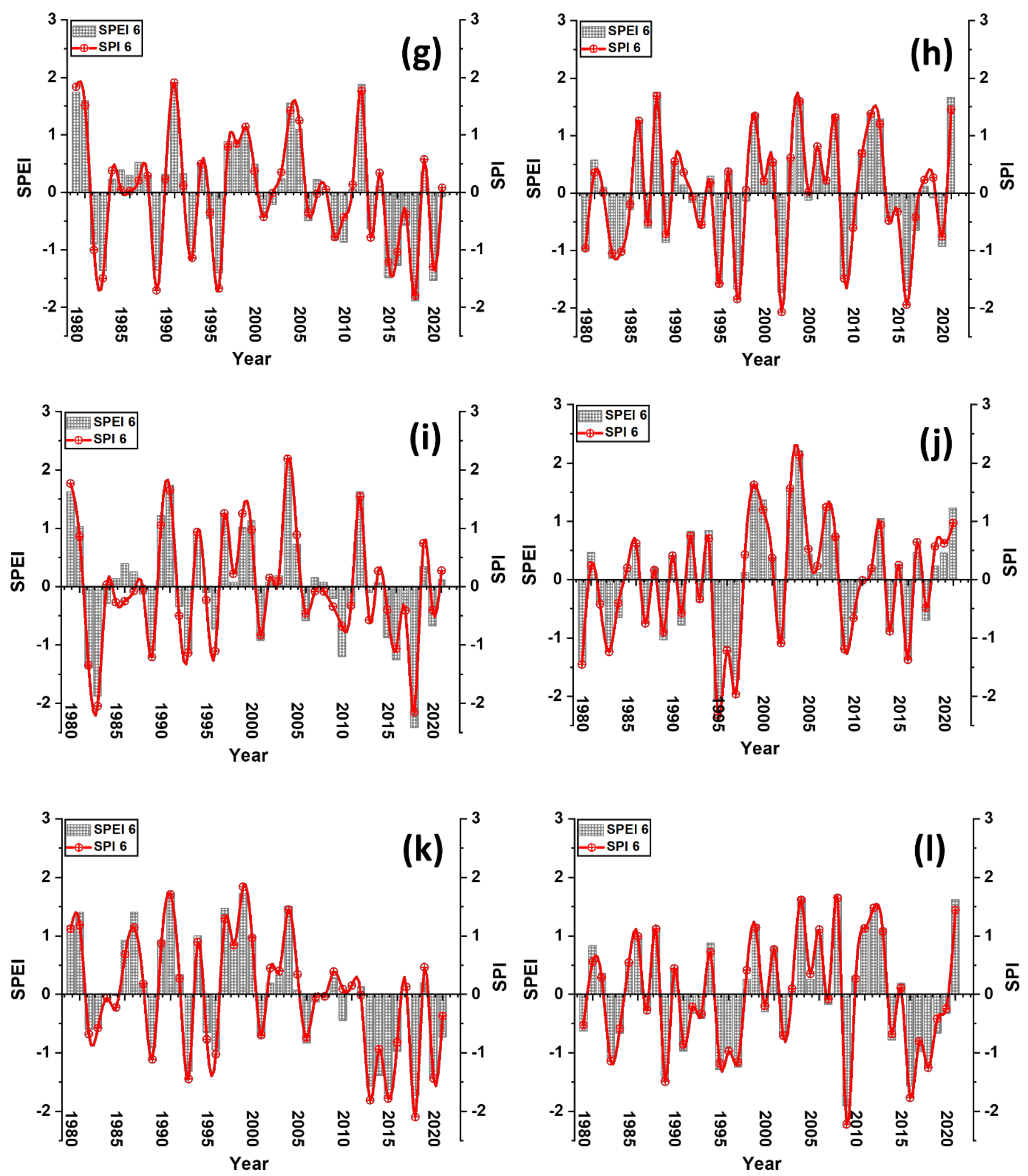

Figure 6. Cont. 

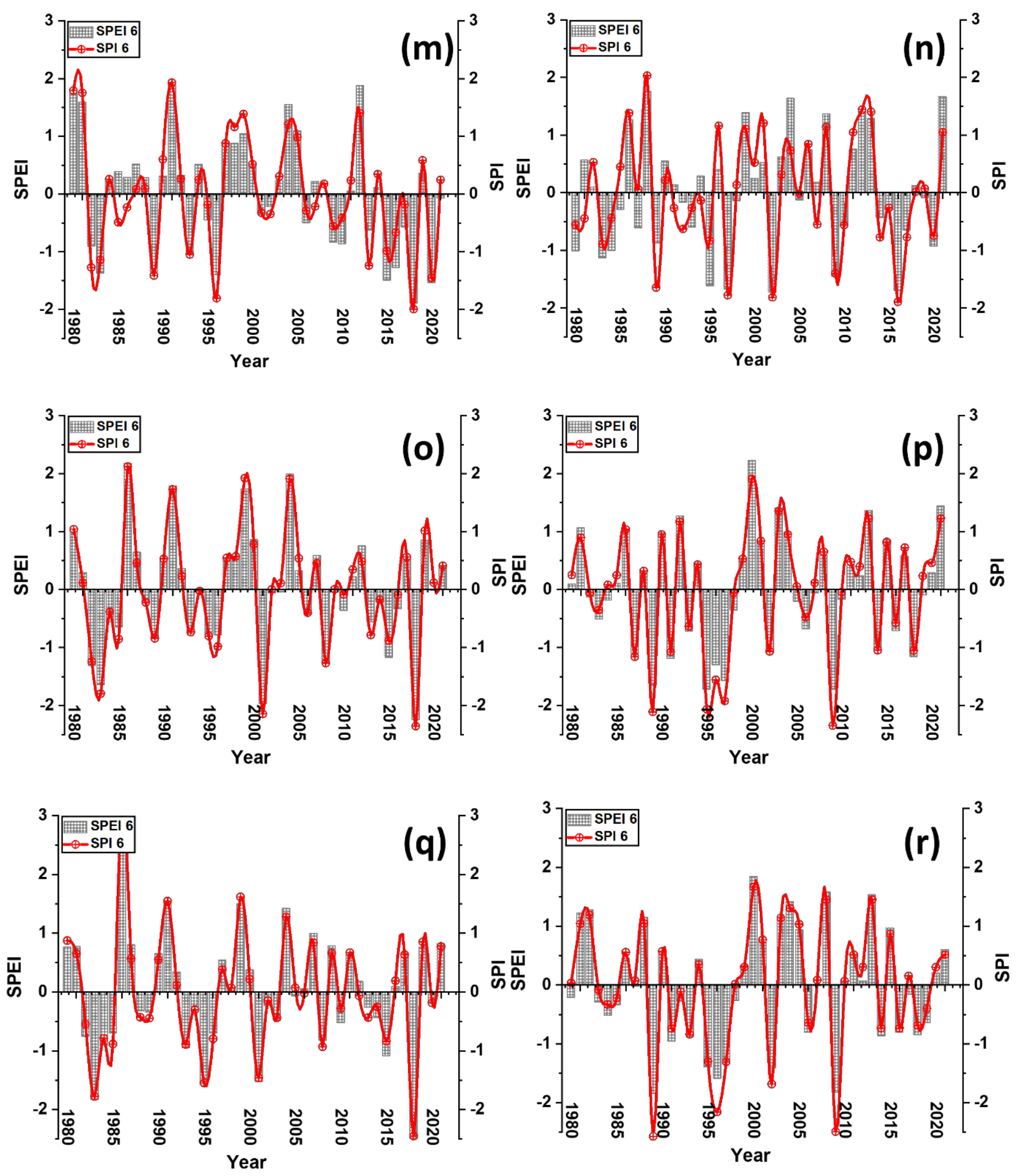

Figure 6. SPEI and SPI 6 (a,b) Gangwon, (c,d) Gyeonggi, (e,f) Jeju, (g,h) North Chungcheong, $(\mathbf{i}, \mathbf{j})$ North Gyeongsang, (k,1) North Jeolla, $(\mathbf{m}, \mathbf{n})$ South Chungcheong, $(\mathbf{o}, \mathbf{p})$ South Gyeongsang, and $(\mathbf{q}, \mathbf{r})$ South Jeolla for the month of June (left) and December (right). 


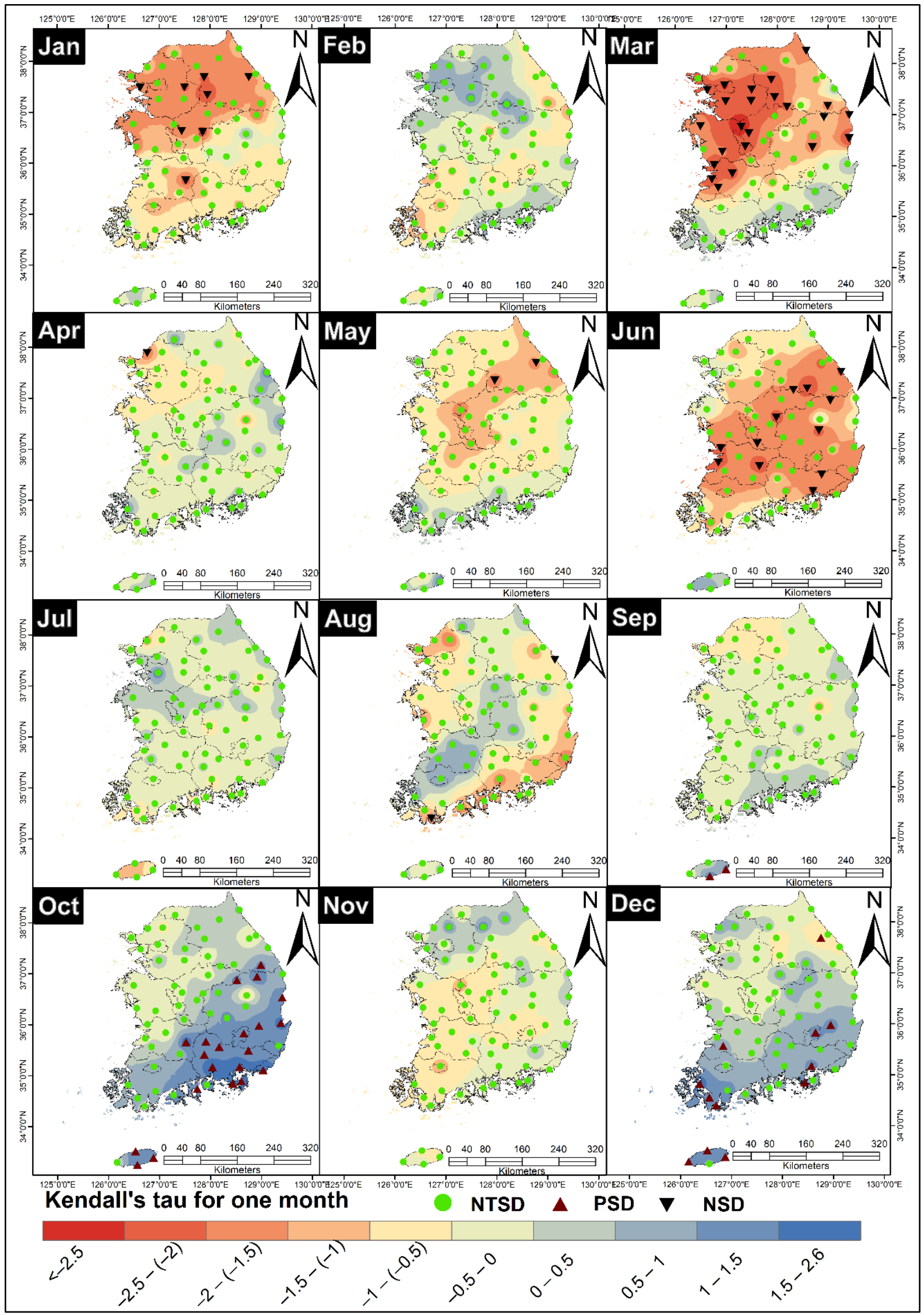

Figure 7. Spatial distribution of Kendall's tau for one-month SPEI series with $95 \%$ significance. Not significantly different (NTSD), positive significant difference (PSD), and negative significant difference (NSD). 


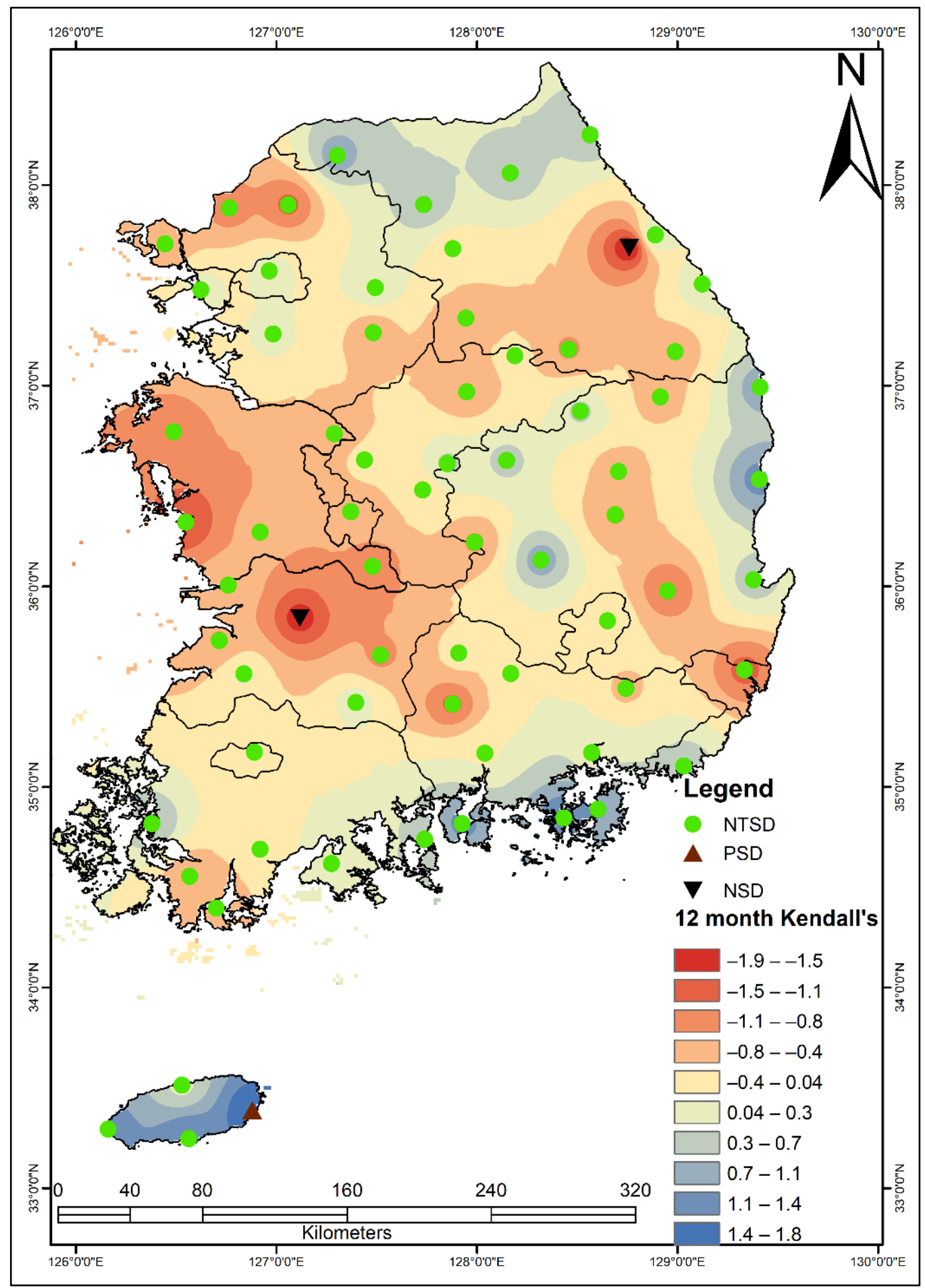

Figure 8. Spatial distribution of Kendall's tau for 12-month SPEI series with 95\% significance. Not significantly different (NTSD), positive significant difference (PSD), and negative significant difference (NSD). 


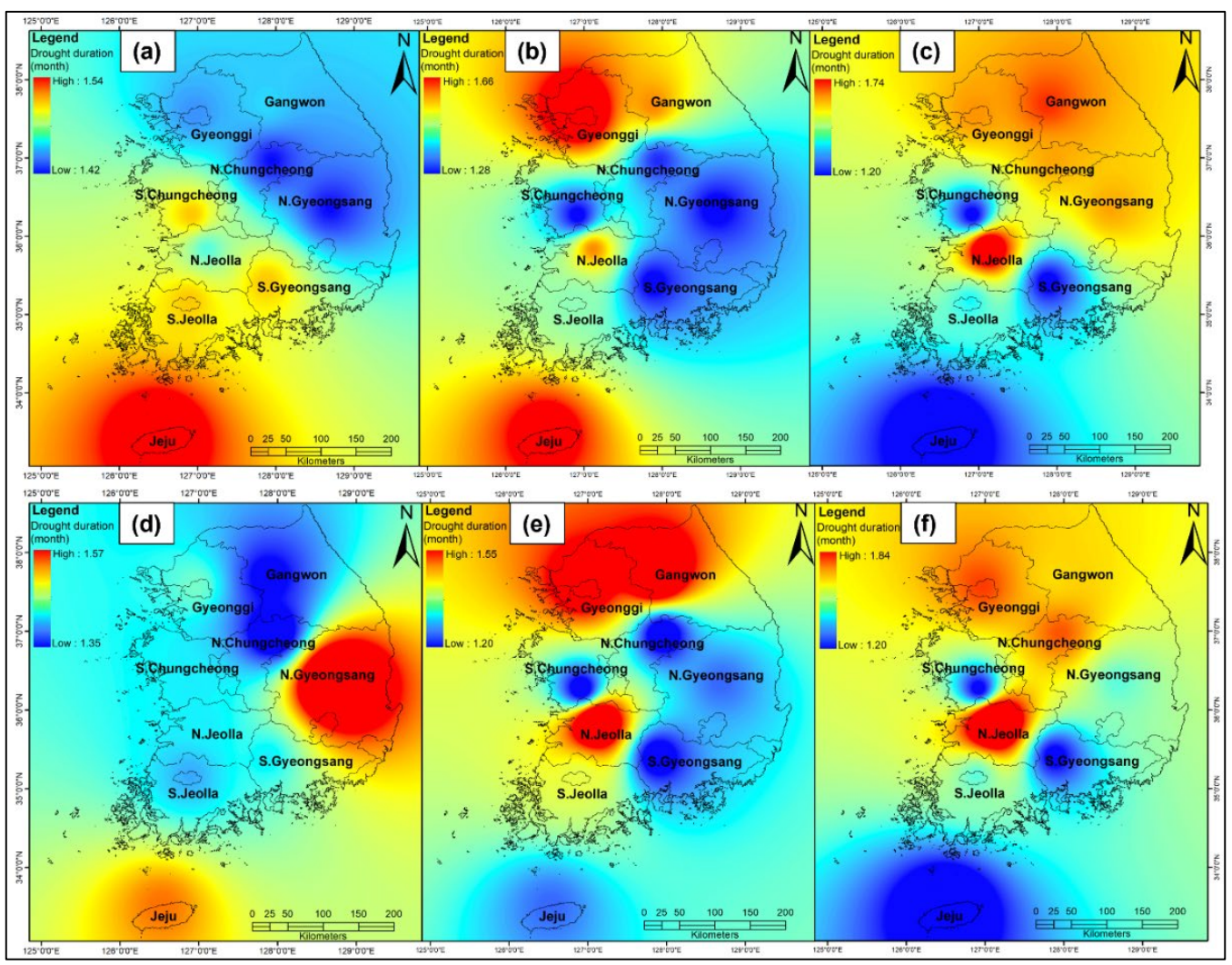

Figure 9. Spatial distribution of average drought duration using SPEI (a) 1-month (b) 6 month, (c) 12-month and SPI (d) 1-month, (e) 6-month, and (f) 12-month.

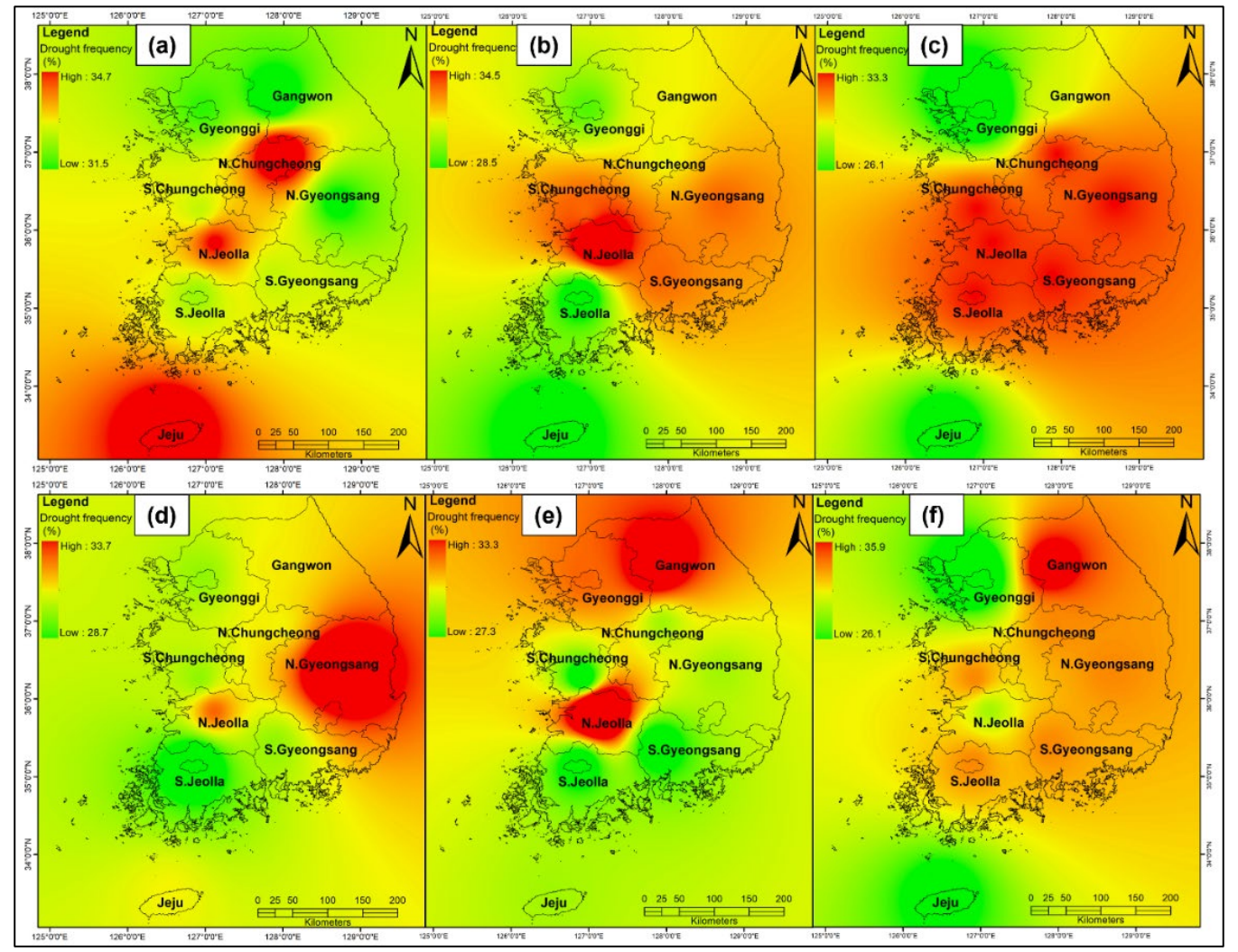

Figure 10. Spatial distribution of drought frequency using SPEI (a) 1-month (b) 6 month, (c) 12-month, and SPI (d) 1-month, (e) 6-month, and (f) 12-month. 


\subsection{Standardized Precipitation Index (SPI)}

The standardized precipitation index (SPI) was developed by Mc Kee in 1993 [37]. It is one of the simplest and most commonly used drought indexes and compares the normalized rainfall with average rainfall to express the deficit and surplus of rainfall for a particular time period, location, and climate [50]. SPI is globally recommended by the World Meteorological Organization (WMO) for drought assessment [51]. SPI can be calculated based on long-term rainfall data for each meteorological station with gamma distribution using the maximum likelihood estimation method for different time scales, i.e., 1, 3, 6, 9, 12, 24 , and 48 months. SPI can be calculated on both short-term and long-term droughts, where its short term application is to assess the drought impact on moisture and precipitation, while the long term SPI is calculated to assess the drought impact on agriculture and water resources, i.e., surface water flow, reservoir, and groundwater supplies [11]. In this study we have discussed both short term SPI (1 and 6 months) and long-term SPI (12 months) to assess and characterize drought in South Korea.

SPI was calculated using the SPEI package in R programming. The specific formula for SPI is given below.

$$
\mathrm{SPI}=y-z / \sigma
$$

To calculate SPI, subtract monthly rainfall $(y)$ from the mean $(z)$ and divide by the standard deviation $(\sigma)$ of rainfall calculated from the monthly time series. Data were normalized using the gamma distribution method, which is suggested by many researchers to calculate the SPI $[52,53]$.

\subsection{Standardized Precipitation Evapotranspiration Index (SPEI)}

The standardized precipitation evapotranspiration index (SPEI) is similar to SPI except for the addition of the mean minimum and mean maximum temperature to rainfall. In the SPEI calculation, we need the monthly water balance, which is based on the difference between rainfall and potential evapotranspiration (PET). PET can be calculated using various parameters, i.e., temperature, relative humidity, solar radiation, air water vapor, and sensible and latent heat flux. However, most of the meteorological stations in the world do not record this kind of data [3]. So as a proxy, we calculated the PET using the Hargreaves method [54], which requires temperature data and the latitude of the concerned meteorological station. The PET was calculated using R programming, and the monthly PET was subtracted from the monthly precipitation data to obtain the water balance.

$$
B_{i}=R_{i}-\mathrm{PET}_{i}
$$

Here, $B$ denotes the water balance deficit or surplus at the $i$ th month, $R$ indicates monthly rainfall at month $i$, and PET is the potential evapotranspiration at the $i$ th month. Now, $B_{i}$ are accumulated for different time scales

$$
C_{m}^{i}=\sum_{k=0}^{i=1}\left(R_{m-k}-\mathrm{PET}_{m-1}\right), m \geq i .
$$

The SPEI was calculated for monthly time scales $i$, for $n$ number of calculations using the SPEI package in $R$ programming.

\subsection{Mann-Kendall (MK)Trend Test}

In the literature, we found many statistical methods [48] for trend detection of time series data. Every method has its own advantages and disadvantages. We used the MannKendall (MK) test to identify the trend in SPI and SPEI for dry and wet conditions. It is a nonparametric statistical method $[48,55]$ recommended by the WMO for trend assessment of hydrological and meteorological variables $[55,56]$. 


\section{Results}

\subsection{Spatiotemporal Rainfall Variability}

The rainfall variability was analyzed based on 70 meteorological stations in South Korea. Most of the meteorological stations in South Korea are located at low elevation with the lowest Pohang $(4 \mathrm{~m})$ and the highest Daegwallyeong $(772 \mathrm{~m})$. We performed statistical analysis on all the meteorological stations to examine the central tendency and dispersion. The highest standard deviation was found for Geoje (525.68 $\mathrm{mm})$, followed by Daegwallyeong (496.69), Seogwipo (454 mm), Namhae (444.52 mm), Changwon $(419.42 \mathrm{~mm})$, and Sancheong (419.75), which revealed high amount of annual rainfall variability at each met station. The lowest amount of annual rainfall variability was found for Yeongcheon (238.6 mm) followed by Daegu (245.2 mm), Uiseong (251.5 mm), Chupungryung (253.42 mm), Andong (260.54 mm), and Yeongdeok $(263.7 \mathrm{~mm})$. The data normality was checked using skewness and kurtosis. Skewness shows the symmetry of the data; Daegu, Gunsan, Gwangju, Inje, Cheonan, Jeongeup, Haenam, and Namhae showed a normal distribution, while Cheongju, Longevity, Andong, Jeonju, Mokpo, Pearl, Boryeong, Geumsan, Imsil, Namwon, Jangheung, Geochang, Hapcheon, Miryang, and Sancheong met stations showed negative skewness, which described negative symmetry from the normal. All other met stations showed a positive skewness, which indicated an increase in the amount of rainfall from the long-term normal. Kurtosis was used to measure the flatness and peaks of the data compared to their normal distribution, in which high (positive) values represents peaks of the data, while low (negative) values indicate the flatness of the data near the mean. Table 3 shows that 43 met stations were flat, while only 27 met stations had a high peak from the normal data.

The inverse distance weightage (IDW) interpolation technique was applied on monthly and annual rainfall data to spatially analyze the rainfall in the study area. The results revealed that in South Korea, $50-60 \%$ of the annual rainfall occurs in summer during June-August, whereas the spring season (March-May) receives 25-30\% of the total annual rainfall (Figure 3). On average, only $20 \%$ of rainfall occurs from September to February. Areas receiving less than $250 \mathrm{~mm}$ of rainfall are arid regions, while rainfall occurring between 250 and $750 \mathrm{~mm}$ and greater than $750 \mathrm{~mm}$ come under the umbrella of semi-arid and humid regions, respectively [57]. Thus, according to this classification, most of South Korea is a humid region; only North Gyeongsang province is arid and semi-arid (Figure 4). From the mean monthly and mean annual rainfall, we can observe that the northern part of the country receives less rainfall compared to the south and coastal regions of South Korea [26] (Figures 3 and 4). Coastal regions of South Korea receive intense amounts of rainfall in the summer season due to typhoon-induced changes [21]. It was also observed that the western part of the country receives more rainfall compared to east, which may be due to the foehn warming phenomena [58]. The eastern and central part of the country have the Taebaek and Sobaek mountain ranges, respectively (encircled part in Figure 4). In mountain ranges, the windward side receives more rainfall compared to the leeward side (mostly on the east side) [58-60]. NGII, (2020) has also discussed the effects of the windward and leeward sides in Korea.

\subsection{2-Month SPI and SPEI}

The SPI and SPEI were applied to analyze the dry and wet situations in the study area during 1979-2020 using 70 meteorological stations' data. Long term SPI and SPEI are the accumulated effect of short-term droughts, thus, we incorporated both short- and long-term SPI and SPEI in this study for the time scale of 1, 6, and 12 months. The 12-month SPI and SPEI revealed drought conditions in South Korea in different years. It was found that in 1982 all provinces except Jeju and North Gyeongsang province experienced moderate drought in both indexes [23] (Figure 5a-i). In the same year, only North Gyeongsang experienced a severe drought condition (Figure 4). Moreover, Jeju province experienced a severe rainfall deficit in 1984 (Figure 5i). 
Extreme drought conditions were observed for South Jeolla in 1988 in the SPI; however, the SPEI a showed moderate drought in South Chungcheong and severe drought conditions in South Jeolla (Figure 5b,h). In the same year, South Gyeongsang, North Jeolla, and Jeju experienced severe drought conditions, according to the SPI and SPEI (Figure 5d,g,i) while North Chungcheong Gangwon, and North Gyeongsang underwent moderate drought, according to the SPI and SPEI (Figure 5a,c,d). Moderate drought conditions were observed in 1994 for Gangwon, Gyeonggi, North and South Chungcheong, and North Jeolla province, with severe drought for North and South Gyeongsang (Figure 5d,e) and South Jeolla (Figure 5h) [23]. In 1995, moderate drought was observed for North Jeolla (Figure 5g) and North and South Gyeongsang (Figure 5d,e), while drought was severe for South Jeolla (Figure 5h) [23]. In Jeju province, moderate drought was noticed for the years of 1996, 1997, 2005, and 2017 in both drought indices (Figure 5i). South Gyeongsang also experienced moderate drought in 1996, but in 2008 and 2017, the province shifted to severe drought conditions (Figure 5e). Gangwon went through a moderate drought in 2001, 2016, and 2019, but the province also faced severe drought conditions in 2014 and 2015 (Figure 5c). Gyeonggi underwent extreme drought in 2014 and 2015, but in 2016 and 2019, the province underwent moderate droughts (Figure $5 f$ ). North and South Chungcheong provinces faced moderate drought conditions in 2001, 2008, and 2019, but a severe drought condition was spotted in 2015 (Figure 5a,b). North Gyeongsang suffered from moderate drought once in the 21st century (2008); athough, it encountered two severe droughts in 2015 and 2017 (Figure 5d). Two provinces (North and South Joella) underwent moderate drought in 2008 and 2013 (Figure 5g) and 2001 and 2008 (Figure 5h), respectively. However, North Joella faced two severe drought years (2015 and 2017) (Figure 5g), and South Joella encountered one in 2017 (Figure 5h).

\subsection{6-Month SPI and SPEI}

In the present study, we calculated the 6-month SPI and SPEI for the months of June and December for South Korea. Figure 6 shows the 6-month drought for June and December for the SPI and SPEI. Gangwon province experienced a moderate drought in the month of June, according to the SPI in 1985, but it was not detected by the SPEI. In 1988, both the SPEI and SPI detected moderate drought, but the severity of the SPI was higher than the SPEI. In 1995, moderate drought was observed, according to the SPI, but it was not detected by the SPEI. However, in 2014, the SPEI spotted moderate drought, but the SPI did not observe it. The SPEI observed severe and extreme drought conditions for the month of June in Gangwon in 2015 and 2017, but the SPI identified moderate and severe drought conditions, respectively (Figure 6a). In the month of December, extreme and severe drought conditions were observed by the SPEI and SPI in Gangwon province for the years of 1979 and 2015, respectively (Figure 6b).

Gyeonggi province experienced three moderate droughts in the month of June for 1988, 1995, and 2000, according to both indices. In 2017, the SPEI spotted an extreme drought condition, but the SPI identified a severe drought condition (Figure 6c). For the month of December, Gyeonggi province went through moderate drought (1988, 1996, and 2016) and severe drought $(1979,2014$, and 2015), according to both indices (Figure 6d). Jeju province experienced five years of moderate drought (1982, 1984, 2002, 2005, and 2013) and two years of severe drought (2000 and 2017), while it was found that the province did not undergo extreme drought for the month of June, according to both indices (Figure 6e). In the month of December, the SPEI showed a severe drought in 1988, but the SPI detected an extreme drought condition. In 2013, the SPEI and SPI revealed extreme drought conditions. Moreover, the province went through five moderate drought years in the month of December, according to both indices (1984, 1994, 1996, 2005, and 2008) (Figure 6f).

North Chungcheong province underwent moderate drought in the month of June 1981, according to the SPI, but it was not detected by the SPEI. The SPI found severe drought in 1982, 1988, and 1995, while the SPEI observed moderate drought. Two more drought years (2014 and 2015) were revealed by both indices (Figure $6 \mathrm{~g}$ ). The month of 
December suffered moderate drought in 1982, 1983, and 2008, according to both indices, while three severe drought years were also detected by the SPEI and SPI (1994, 1996, and 2015). An extreme drought condition was observed by the SPI in 2001, but it was not seen in the SPEI (Figure 6h). South Gyeongsang province went through two severe droughts (1982 and 2000) and one extreme drought condition (2017) for the month of June, according to both indices. While in 1981 and 2000, the province experienced moderate drought (Figure 6i). Both indices revealed five years of moderate drought $(1986,1990$, 2001, 2013, and 2017) in the month of December, while one severe drought (1996) was also detected. The SPEI discovered three severe drought years (1988, 1994, and 2008), but the SPI showed extreme drought in the same years (Figure 6j). For the month of June, North Jeolla province showed two moderate drought years (1992 and 2019) and two severe drought years (2012 and 2014), according to both indices (Figure 6k). However, December revealed five moderate drought years $(1982,1988,1994,1996$, and 2017) and one severe drought year (2015). While in 2008, the SPI detected an extreme drought condition, but the SPEI revealed a severe drought condition (Figure 61). South Chungcheong did not experience any extreme drought conditions in the months of June and December (Figure 6m,n). However, three moderate drought years (1982, 1988, and 1992) in the month of June (Figure 6m) and one moderate drought year (2008) in the month of December (Figure 6n) were found by both indices. Furthermore, one severe drought year was (2017) detected for the month of June (Figure 6m) and four severe drought years (1994, 1996, 2001, and 2015) were found for the month of December (Figure 6n). Not a single year was detected as an extreme drought condition in both indices for the month of June and December (Figure 6m,n). South Gyeongsang was affected by two moderate droughts (1981 and 2007) and two severe droughts (1982 and 2000) for the month of June, according to both indices (Figure 60). For the month of December, the province revealed four moderate drought years (1986, 1990, 2013, and 2017). In 1996, the province was affected by a severe drought condition. It was also shown that in 1988, 1994, and 2008, the SPEI detected a severe drought, but the SPI showed an extreme drought condition (Figure $6 \mathrm{p}$ ). South Jeolla was affected by two severe drought years (1982 and 1994) and one extreme drought year (2017) for the month of June, according to both indices. In 2000, the SPEI detected severe drought conditions in South Jeolla province, but the SPI failed to detect this (Figure 6q). For the month of December, the SPEI detected three severe drought years $(1988,1995$, and 2008), but the SPI found extreme drought in the same years. Two moderate drought years (1994 and 1996) were also observed by both indices (Figure 6r). In this study, a different pattern of SPI and SPEI was found for the 6-month time scale, which is in contrast to another study [25]. The over and underestimation of drought by SPI may be due to a single variable (rainfall) [27]; however, SPEI performed well in the detection of drought events, due to the additional PET parameter, which is also discussed by Uddin et al., (2020) [25].

\subsection{Mann-Kendall Trend Test}

In the present research, we utilized the MK test to analyze the trend in the 1- and 12-month SPEI and SPI series. However, we noticed a similar trend, which is why we did not incorporate the SPI trend results. The trend results were interpolated using IDW technique. We calculated the trend using a 95\% significance level with a $p$ value of $\leq 0.05$ for both the 1- and 12-month SPEI series. In the trend test, positive values indicate wet conditions, while negative values indicate dry condition.

In the one-month SPEI series, a positive trend was found in the months of February (Northern part) and March (Southern part); whereas, in September, October, and December there was a positive trend in whole country. A significant positive trend (wet conditions) was revealed in the months of September, October, and December in 2, 20, and 11 meteorological stations, respectively. In the month of February, there was no significant trend at any meteorological station, and most parts of the country had wet conditions, except some parts in the southeast and west. In the month of July, there was also no significant trend, but there were wet conditions except in Jeju province. In the month of November, no 
significant trend was detected, but it also showed nominal wet conditions in the country. It was observed that the country has faced a negative trend in the month of January, (North), March (except the Southern part), April (North-East), June (whole country, except Jeju province), and August (North-East and South). A significant negative trend was found for the month of January (8 met stations), March (22), April (1), May (2), June (12), and August (2) [61]. Azam et al., (2018a) [26] also found the highest negative autocorrelation in the summer season and the least in the winter months.

More than $50 \%$ of the country's rainfall occurs in the months of June, July, and August [21,26]; however, in the present study, we found that the months of June and August had significant droughts, which is an alarming situation due to increasing temperature and the shortened monsoon period [21,26,62]. Many parts of South Korea receive precipitation in the form of snowfall from December-February, but in the month of January a significant negative trend was observed (dry condition), which is also a frightening situation because melt snow contributes to river flow in the summer season; thus, dry conditions in winter can ultimately cause water shortages in the summer season for the agriculture sector.

The 12-month SPEI results revealed drying conditions in the South-West, South-East, and East-Central part of the country [26], while wet conditions were detected in North, West, and in Jeju province. Jeonju and Daegwallyeong met stations encountered a significant decreasing trend (dry condition), while Seongsan experienced a significant increasing trend (wet condition), and all other met stations did not show any significant trend.

\subsection{Spatial Distribution of Drought Characteristics}

In this study, we calculated the characteristics of drought (frequency and duration) for both indices at different time scales; then, we interpolated it with an IDW technique (Figures 9 and 10). It was noticed that the drought duration for the one-month SPEI and SPI was different in spatial distribution. In the SPEI, the highest drought duration was detected for Jeju province (Figure 9a), while Jeju province experienced moderate drought duration, according to the SPI (Figure 8). It was also spotted that North Gyeongsang fell under the highest drought duration in the one-month SPI index (Figure 9d), but it fell under the lowest drought duration in the 1-month SPEI (Figure 9a). Similarly for the 6-month data, the drought duration was high for Jeju province, according to the SPEI (Figure $9 b$ ), but it fell under moderate drought duration, according to the SPI (Figure 9e). The 12-month SPI and SPEI drought duration were slightly different (Figure $9 \mathrm{c}, \mathrm{f}$ ).

For a drought frequency of 1-month, according to the SPEI, the highest frequency was distributed in the central part (North Chungcheong, North Jeolla) and in the south (Jeju province) (Figure 10a); while, according to the SPI, the highest drought frequency was observed for North Gyeongsang province (Figure 10d), which is in contrast to a study conducted by Azam et al., (2018a) [26]. At the 6-month time scale in the SPEI, a moderate to highest drought frequency was centered on North and South Gyeongsang, North and South Chungcheong, and North Jeolla province (Figure 10b). However, in the SPI, the moderate to highest frequency was distributed in Gangwon, Gyeonggi, and the North Jeolla province (Figure 10e). At the 12-month time scale in the SPEI, the highest drought frequency was distributed in all provinces except Gyeonggi, Gangwon, and Jeju (Figure 10c), while in the SPI, it was only found for Gangwon province (Figure 10f).

\section{Discussion}

Shortening of the summer monsoon period or less rainfall for a longer period are major causes of drought in South Korea, because more than $50 \%$ of the total rainfall occurs in the summer season, which is shrinking [21,26]. In the present study, drought conditions were witnessed in the central, eastern, and western coastal regions of the country, according to the 12-month SPEI. Azam et al., (2018a) [26] also found increasing drought conditions in the mid-latitudes, southeast, and northeast coastal region, and west side of the country. The results revealed that the summer months had significant drought conditions as compared to the winter months, which is consistent with a study conducted 
by Azam et al., (2018a) [26]. This is due to the decreasing amount of rainfall in the shortened monsoon period.

In this study, we examined that in last decade the intensity of drought has increased in South Korea and; this was also discussed and projected by Kim et al., (2012) [63]. Lee et al., (2021) [64] also observed and discussed that in last ten years drought events have increased in South Korea and found severe drought conditions in 2013 and 2017; the current study also detected severe drought in those years, as well as increasing drought frequency. Hong et al. (2016) [23] discussed that from early 2014, the precipitation in South Korea has decreased extensively at record levels, which has triggered drought conditions in Korea, which lasted for more than 20 months. Bae et al., (2019) [65] found that the pattern of rainfall is changing every $4-5$ years, which endorses the drought events occurring in South Korea every 5-6 years since 1960 [23]. Zhang and Zhou [66] revealed that drought conditions in Japan, China, and the Korean peninsula are usually dominated by East Asian monsoon variability. Choi et al., (2013) [67] explained that in the spring season (April-May), the amount of rainfall increases temporarily due to the northern hemisphere atmospheric circulation, but the rainfall in the spring season decreases due to the weakening of the subtropical western North Pacific high (SWNPH), which can cause droughts in the spring season [68]. Byun HR (1996) [69] found that deepening of cyclones and abnormally low and high temperatures can cause summer droughts in Korea. Choi et al., (2011) [70] observed that intensified drought in the summer season occurs in Northeast Asia due to the northeasterlies cyclonic and anticyclonic circulation. Park and Schubert (1997) [71] revealed that the 1994 drought in East Asia was forced as a result of the deficit of the summer/monsoon rainfall with an early development of upper level anticyclonic flow to east of the Tibetan plateau. Bae et al., (2018) [72] detected intensive drought in the 1-month SPEI for almost all met stations in Korea, which was also consistent with the 1-month SPEI and SPI results calculated in this study. According to the Korean climate change and drought survey report, Korea faced drought events in 1981-1982, 1994-1995, 2001-2007, and 2014-2015, which was also reflected in this study using SPI and SPEI for 1982, 1988, 1994, 2001, 2008, and 2014-2015 [72]. Almost the same years of drought have been detected in other studies conducted in the Asian region [4,11]. Hong et al., (2016) [23] discussed the 2014-2015 drought as the worst in the history of South Korea in which annual rainfall decreased $35-50 \%$ from its normal, and the same years were detected as severe to extreme drought in this study for six out of a total of nine provinces in South Korea in the results of the 12-month SPI and SPEI. Moreover, the 1994-1995 drought event was also found in the present study for all regions, except Jeju province. However, the 1981-1982 drought event was not clearly observed by both the indices. Comparing the drought events with the El Niño-Southern Oscillation (ENSO), it was found that most of the drought events were consistent with moderate, strong, and very strong ENSO events [73]. It is expected that in future, the severity of droughts will increase in South Korea due to climate change [53]. It was shown in the present study that droughts occur frequently throughout the year in different parts of the country with various intensities, which was also revealed by Azam et al., (2018a) [26]. It was noted that the frequency of drought was high in the 1-month SPEI for the southern and central regions of the country, which is consistent with a study conducted by Bae et al., (2018) [72]; however, the 12-month SPI drought frequency was high in the northeast region, which was in contrast with Azam et al., (2018a) [26]. Jang (2018) [27] projected that the 12-month drought intensity would increase in Daegu, which is in contrast with this study; however, we noticed that in the 1-month drought data, the duration and frequency were high for Daegu [27].

We compared the SPI and SPEI, and it was found that the SPEI performed better than the SPI, which is consistent with a study performed by Sung et al., (2020) [29], because SPEI incorporates an additional evapotranspiration parameter for drought identification. Jang (2018) [27] also discussed that the high temperature influences the evapotranspiration, leading to the possibility of drought conditions, which cannot be detected only with precipitation, as in case of SPI. 


\section{Conclusions}

In this study, we evaluated the spatial and temporal changes of drought in South Korea using SPEI and SPI for the period of 1979-2020 using 70 meteorological stations. We analyzed the rainfall variability and found the highest variability for the Geoje met station and the lowest for Yeongcheon. It was observed that the northern part of the country received less rainfall than the southern part. The western part of the country also received more rainfall due to the mountain ranges in the eastern part of the country, which cause foehn warming phenomena. We calculated SPI and SPEI for 1, 6, and 12-month time series for dry and wet conditions and found that 1982, 1988, 1994, 2001 2008, 2015, and 2017 were the dry years in the 12-month time series, according to both indices. In the 6-month time series the highest number of mixed dry events (moderate, severe, and extreme drought) were found in the period of 2013-2017. In the one-month time series, a significant positive trend was observed for the months of September, October, and December, while a significant negative trend was detected in the months of January, March, April, May, June, and August. It was noticed that October was the wettest month, while March and June were the driest months in the one-month time series. In the 12-month time series, significant dry conditions were observed for Jeonju and Daegwallyeong met stations, and significant wet conditions were observed for Seongsan met station. The climatic variability needs longer time data records, but, unfortunately, consistent data for South Korea was only available from 1979 onwards. Trend analysis based on longer temporal data records will provide more authentic results. However, this study provided a reference to evaluate the different types of droughts for the long term. There is a dire need to formulate proper strategies and make policies to cope with the changing climate and its related disasters. We plan to study different types of droughts in more detail using future projection data (GCM) of precipitation and temperature. We also plan to study the spatiotemporal changes in aridity and its influence of land use using past and future projection data.

Author Contributions: Conceptualization M.F.U.M. and B.G.L., Formal Analysis, Visualization, M.F.U.M., N.F. and G.R., Methodology, Visualization, Writing Original draft, M.F.U.M., Writing, review and editing G.R., S.M. and B.G.L., Project administration, Supervision \& Funding acquisition, B.G.L. All authors have read and agreed to the published version of the manuscript.

Funding: This research was supported by the Basic research program through the National Research Foundation (NRF) funded by the Ministry of Education (2019R1A6A1A10072987).

Institutional Review Board Statement: Not applicable.

Informed Consent Statement: Not applicable.

Data Availability Statement: The data acquired from Korean Meteorological Administration which can not be provided openly. The data can be requested from the first author.

Acknowledgments: The principal author greatly acknowledges the Korean Meteorological Administration (KMA) for providing rainfall and temperature data. The first author is also thankful to Asif Mehmood (Department of Computer Engineering, Jeju National University, Jeju, Korea) for helping in data cleaning and curation.

Conflicts of Interest: The authors declare no conflict of interest.

\section{References}

1. Bonaccorso, B.; Bordi, I.; Cancelliere, A.; Rossi, G.; Sutera, A. Spatial Variability of Drought: An Analysis of the SPI in Sicily. Water Resour. Manag. 2003, 17, 273-296. [CrossRef]

2. Poonia, V.; Goyal, M.K.; Jha, S.; Dubey, S. Terrestrial ecosystem response to flash droughts over India. J. Hydrol. 2022, 605, 127402. [CrossRef]

3. Rahman, G.; Rahman, A.-U.; Ullah, S.; Dawood, M.; Moazzam, M.F.U.; Lee, B.G. Spatio-temporal characteristics of meteorological drought in Khyber Pakhtunkhwa, Pakistan. PLoS ONE 2021, 16, e0249718. [CrossRef] [PubMed]

4. Khan, A.A.; Zhao, Y.; Rahman, G.; Rafiq, M.; Moazzam, M.F.U. Spatial and Temporal Analysis of Rainfall and Drought Condition in Southwest Xinjiang in Northwest China, Using Various Climate Indices. Earth Syst. Environ. 2021, 5, 201-216. [CrossRef] 
5. Yang, Y.; Gan, T.Y.; Tan, X. Spatiotemporal changes of drought characteristics and their dynamic drivers in Canada. Atmos. Res. 2020, 232, 104695. [CrossRef]

6. Rafiq, M.; Li, Y.C.; Cheng, Y.; Rahman, G.; Ullah, I.; Ali, A. Spatial and temporal fluctuation of rainfall and drought in Balochistan province, Pakistan. Arab. J. Geosci. 2022, 15, 214. [CrossRef]

7. Dai, A. Increasing drought under global warming in observations and models. Nat. Clim. Chang. 2013, 3, 52-58. [CrossRef]

8. Sönmez, F.K.; Koemuescue, A.U.; Erkan, A.; Turgu, E. An analysis of spatial and temporal dimension of drought vulnerability in Turkey using the standardized precipitation index. Nat. Hazards 2005, 35, 243-264. [CrossRef]

9. Ashraf, M.; Routray, J.K. Spatio-temporal characteristics of precipitation and drought in Balochistan Province, Pakistan. Nat. Hazards 2015, 77, 229-254. [CrossRef]

10. Khadr, M. Temporal and spatial analysis of meteorological drought characteristics in the upper Blue Nile river region. Hydrol. Res. 2016, 48, 265-276. [CrossRef]

11. Rahman, G.; Dawood, M. Spatial and temporal variation of rainfall and drought in Khyber Pakhtunkhwa Province of Pakistan during 1971-2015. Arab. J. Geosci. 2018, 11, 46. [CrossRef]

12. Zarch, M.A.A.; Malekinezhad, H.; Mobin, M.H.; Dastorani, M.T.; Kousari, M.R. Drought monitoring by reconnaissance drought index (RDI) in Iran. Water Resour. Manag. 2011, 25, 3485-3504. [CrossRef]

13. Hosseini, T.S.M.; Hosseini, S.A.; Ghermezcheshmeh, B.; Sharafati, A. Drought hazard depending on elevation and precipitation in Lorestan, Iran. Theor. Appl. Climatol. 2020, 142, 1369-1377. [CrossRef]

14. Ullah, I.; Ma, X.; Yin, J.; Asfaw, T.G.; Azam, K.; Syed, S.; Liu, M.; Arshad, M.; Shahzaman, M. Evaluating the meteorological drought characteristics over Pakistan using in situ observations and reanalysis products. Int. J. Climatol. 2021, 41, 4437-4459. [CrossRef]

15. Ullah, I.; Ma, X.; Yin, J.; Saleem, F.; Syed, S.; Omer, A.; Habtemicheal, B.A. Influence of large-scale circulation and interannual modes of climate variability on seasonal drought characteristics over Pakistan. Res. Sq. 2021, in press. [CrossRef]

16. Mishra, A.; Singh, V.; Desai, V. Drought characterization: A probabilistic approach. Stoch. Environ. Res. Risk Assess. 2009, 23, 41-55. [CrossRef]

17. Ahmed, K.; Shahid, S.; Nawaz, N. Impacts of climate variability and change on seasonal drought characteristics of Pakistan. Atmos. Res. 2018, 214, 364-374. [CrossRef]

18. Uwimbabazi, J.; Jing, Y.; Iyakaremye, V.; Ullah, I.; Ayugi, B. Observed Changes in Meteorological Drought Events during 1981-2020 over Rwanda, East Africa. Sustainability 2022, 14, 1519. [CrossRef]

19. Chung, Y.-S.; Yoon, M.-B.; Kim, H.-S. On Climate Variations and Changes Observed in South Korea. Clim. Chang. 2004, 66, 151-161. [CrossRef]

20. Hertel, T.W.; de Lima, C.Z. Climate impacts on agriculture: Searching for keys under the streetlight. Food Policy 2020, 95, 101954. [CrossRef]

21. Kim, J.-S.; Jain, S. Precipitation trends over the Korean peninsula: Typhoon-induced changes and a typology for characterizing climate-related risk. Environ. Res. Lett. 2011, 6, 034033. [CrossRef]

22. Azam, M.; Kim, H.S.; Maeng, S.J. Development of flood alert application in Mushim stream watershed Korea. Int. J. Disaster Risk Reduct. 2017, 21, 11-26. [CrossRef]

23. Hong, I.; Lee, J.-H.; Cho, H.-S. National drought management framework for drought preparedness in Korea (lessons from the 2014-2015 drought). Water Policy 2016, 18, 89-106. [CrossRef]

24. Wu, Z.; Xu, H.; Li, Y.; Wen, L.; Li, J.; Lu, G.; Li, X. Climate and drought risk regionalisation in China based on probabilistic aridity and drought index. Sci. Total Environ. 2018, 612, 513-521. [CrossRef]

25. Uddin, M.J.; Hu, J.; Islam, A.R.M.T.; Eibek, K.U.; Nasrin, Z.M. A comprehensive statistical assessment of drought indices to monitor drought status in Bangladesh. Arab. J. Geosci. 2020, 13, 323. [CrossRef]

26. Azam, M.; Maeng, S.J.; Kim, H.S.; Lee, S.W.; Lee, J.E. Spatial and temporal trend analysis of precipitation and drought in South Korea. Water 2018, 10, 765. [CrossRef]

27. Jang, D. Assessment of meteorological drought indices in Korea using RCP 8.5 scenario. Water 2018, 10, 283. [CrossRef]

28. Kwon, M.; Kwon, H.-H.; Han, D. Spatio-temporal drought patterns of multiple drought indices based on precipitation and soil moisture: A case study in South Korea. Int. J. Climatol. 2019, 39, 4669-4687. [CrossRef]

29. Sung, J.H.; Park, J.; Jeon, J.-J.; Seo, S.B. Assessment of inter-model variability in meteorological drought characteristics using CMIP5 GCMs over South Korea. KSCE J. Civ. Eng. 2020, 24, 2824-2834. [CrossRef]

30. Gopalakrishnan, C. Water and disasters: A review and analysis of policy aspects. Int. J. Water Resour. Dev. 2013, 29, $250-271$. [CrossRef]

31. Ghozat, A.; Sharafati, A.; Hosseini, S.A. Satellite-based monitoring of meteorological drought over different regions of Iran: Application of the CHIRPS precipitation product. Environ. Sci. Pollut. Res. 2022, 1-18. [CrossRef]

32. Kousari, M.R.; Dastorani, M.T.; Niazi, Y.; Soheili, E.; Hayatzadeh, M.; Chezgi, J. Trend Detection of Drought in Arid and Semi-Arid Regions of Iran Based on Implementation of Reconnaissance Drought Index (RDI) and Application of Non-Parametrical Statistical Method. Water Resour. Manag. 2014, 28, 1857-1872. [CrossRef]

33. Yaseen, Z.M.; Ali, M.; Sharafati, A.; Al-Ansari, N.; Shahid, S. Forecasting standardized precipitation index using data intelligence models: Regional investigation of Bangladesh. Sci. Rep. 2021, 11, 3435. [CrossRef] 
34. IPCC. Climate Change 2007: The Physical Science Basis; Solomon, S., Ed.; Contribution of Working Group I to the Fourth Assessment Report of the Intergovernmental Panel on Climate Change; Cambridge University Press: Cambridge, UK, 2007.

35. Rahman, G.; Rahman, A.U.; Anwar, M.M.; Dawood, M.; Miandad, M. Spatio-temporal analysis of climatic variability, trend detection, and drought assessment in Khyber Pakhtunkhwa, Pakistan. Arab. J. Geosci. 2021, 15, 81. [CrossRef]

36. Malik, A.; Rai, P.; Heddam, S.; Kisi, O.; Sharafati, A.; Salih, S.Q.; Al-Ansari, N.; Yaseen, Z.M. Pan Evaporation Estimation in Uttarakhand and Uttar Pradesh States, India: Validity of an Integrative Data Intelligence Model. Atmosphere 2020, 11, 553. [CrossRef]

37. McKee, T.B.; Doesken, N.J.; Kleist, J. The relationship of drought frequency and duration to time scales. In Proceedings of the 8th Conference on Applied Climatology, Anaheim, CA, USA, 17-22 January 1993.

38. Vicente-Serrano, S.M.; Beguería, S.; López-Moreno, J.I. A multiscalar drought index sensitive to global warming: The standardized precipitation evapotranspiration index. J. Clim. 2010, 23, 1696-1718. [CrossRef]

39. Palmer, W.C. Meteorological Drought; U.S. Department of Commerce, Weather Bureau: Washington, DC, USA, 1965 ; Volume 30.

40. Tsakiris, G. Meteorological Drought Assessment; Paper Prepared for the Needs of the European Research Program MEDROPLAN; European Union: Zaragoza, Spain, 2004.

41. Palmer, W.C. Keeping Track of Crop Moisture Conditions, Nationwide: The New Crop Moisture Index. Weatherwise 1968, 21, 156-161. [CrossRef]

42. Song, Y.H.; Chung, E.S.; Shahid, S. Spatiotemporal differences and uncertainties in projections of precipitation and temperature in South Korea from CMIP6 and CMIP5 general circulation models. Int. J. Climatol. 2021, 41, 5899-5919. [CrossRef]

43. Jung, H.C.; Kang, D.-H.; Kim, E.; Getirana, A.; Yoon, Y.; Kumar, S. Towards a soil moisture drought monitoring system for South Korea. J. Hydrol. 2020, 589, 125176. [CrossRef]

44. Jung, I.-W.; Bae, D.-H.; Kim, G. Recent trends of mean and extreme precipitation in Korea. Int. J. Climatol. 2011, 31, 359-370. [CrossRef]

45. Park, S.; Im, J.; Park, S.; Rhee, J. Drought monitoring using high resolution soil moisture through multi-sensor satellite data fusion over the Korean peninsula. Agric. For. Meteorol. 2017, 237, 257-269. [CrossRef]

46. Azam, M.; Park, H.K.; Maeng, S.J.; Kim, H.S. Regionalization of Drought across South Korea Using Multivariate Methods. Water 2018, 10, 24. [CrossRef]

47. Sung, J.H.; Chung, E.-S.; Kim, Y.; Lee, B.-R. Meteorological hazard assessment based on trends and abrupt changes in rainfall characteristics on the Korean peninsula. Theor. Appl. Climatol. 2017, 127, 305-326. [CrossRef]

48. Tan, C.; Yang, J.; Li, M. Temporal-Spatial Variation of Drought Indicated by SPI and SPEI in Ningxia Hui Autonomous Region, China. Atmosphere 2015, 6, 1399-1421. [CrossRef]

49. Ullah, I.; Ma, X.; Yin, J.; Saleem, F.; Syed, S.; Omer AHabtemicheal, B.A.; Liu, M.; Arshad, M. Observed changes in seasonal drought characteristics and their possible potential drivers over Pakistan. Int. J. Climatol. 2021, in press. [CrossRef]

50. Maeng, S.J.; Azam, M.; Kim, H.S.; Hwang, J.H. Analysis of changes in spatio-temporal patterns of drought across South Korea. Water 2017, 9, 679. [CrossRef]

51. Li, W.; Duan, L.; Wang, W.; Wu, Y.; Liu, T.; Quan, Q.; Chen, X.; Yin, H.; Zhou, Q. Spatiotemporal characteristics of drought in a semi-arid grassland over the past 56 years based on the Standardized Precipitation Index. Meteorol. Atmos. Phys. 2021, 133, 41-54. [CrossRef]

52. Kim, C.J.; Park, M.J.; Lee, J.H. Analysis of climate change impacts on the spatial and frequency patterns of drought using a potential drought hazard mapping approach. Int. J. Climatol. 2014, 34, 61-80. [CrossRef]

53. Lee, J.H.; Kim, C.J. A multimodel assessment of the climate change effect on the drought severity-duration-frequency relationship. Hydrol. Process. 2013, 27, 2800-2813. [CrossRef]

54. Hargreaves, G.H.; Samani, Z.A. Estimating potential evapotranspiration. J. Irrig. Drain. Div. 1982, 108, 225-230. [CrossRef]

55. Li, Y.; Wang, Z.; Zhang, Y.; Li, X.; Huang, W. Drought variability at various timescales over Yunnan Province, China: 1961-2015. Theor. Appl. Climatol. 2019, 138, 743-757. [CrossRef]

56. Liu, Z.; Wang, Y.; Shao, M.; Jia, X.; Li, X. Spatiotemporal analysis of multiscalar drought characteristics across the Loess Plateau of China. J. Hydrol. 2016, 534, 281-299. [CrossRef]

57. Khan, F.K. Pakistan Geography Economy and People, 4th ed.; Oxford University Press: Karachi, Pakistan, 2015.

58. Elvidge, A.D.; Renfrew, I.A. The causes of foehn warming in the lee of mountains. Bull. Am. Meteorol. Soc. 2016, 97, 455-466. [CrossRef]

59. Means, T. The Windward Versus Leeward Side of a Mountain. 2020. Available online: https://www.thoughtco.com/leewardand-windward-sides-of-mountain-3444015 (accessed on 15 January 2022).

60. National Geographic Information Institute. The National Atlas of Korea; NGII: Suwon, Korea, 2020.

61. Kim, D.W.; Byun, H.R.; Choi, K.S.; Oh, S.B. A Spatiotemporal Analysis of Historical Droughts in Korea. J. Appl. Meteorol. Climatol. 2011, 50, 1895-1912. [CrossRef]

62. Won, J.; Kim, S. Future drought analysis using SPI and EDDI to consider climate change in South Korea. Water Supply 2020, 20, 3266-3280. [CrossRef]

63. Kim, B.S.; Sung, J.H.; Kang, H.S.; Cho, C.H. Assessment of Drought Severity over South Korea using Standardized Precipitation Evapo-transpiration Index (SPEI). J. Korea Water Resour. Assoc. 2012, 45, 887-900. [CrossRef] 
64. Lee, S.; Lee, S.J.; Jang, K.; Chun, J.-H. Drought Monitoring Based on Vegetation Type and Reanalysis Data in Korea. Atmosphere 2021, 12, 170. [CrossRef]

65. Bae, H.; Ji, H.; Lim, Y.J.; Ryu, Y.; Kim, M.H.; Kim, B.J. Characteristics of drought propagation in South Korea: Relationship between meteorological, agricultural, and hydrological droughts. Nat. Hazards 2019, 99, 1-16. [CrossRef]

66. Zhang, L.; Zhou, T. Drought over East Asia: A review. J. Clim. 2015, 28, 3375-3399. [CrossRef]

67. Choi, K.S.; Kang, S.D.; Kim, H.D. Spatiotemporal variability of April rainfall in Korea by western Pacific teleconnection pattern. Int. J. Climatol. 2013, 33, 1168-1177. [CrossRef]

68. Kim, S.; Park, C.; Kim, M. The regime shift of the northern hemispheric circulation responsible for the spring drought in Korea. Asia-Pac. J. Atmos. Sci. 2005, 41, 571-585.

69. Byun, H. On the atmospheric circulation caused the drought in Korea. J. Korean Meteor. Soc. 1996, 32, 454-469.

70. Choi, K.S.; Oh, S.B.; Byun, H.R.; Kripalani, R.; Kim, D.-W. Possible linkage between East Asian summer drought and North Pacific oscillation. Theor. Appl. Climatol. 2011, 103, 81-93. [CrossRef]

71. Park, C.K.; Schubert, S.D. On the Nature of the 1994 East Asian Summer Drought. J. Clim. 1997, 10, 1056-1070. [CrossRef]

72. Bae, S.; Lee, S.H.; Yoo, S.H.; Kim, T. Analysis of Drought Intensity and Trends Using the Modified SPEI in South Korea from 1981 to 2010. Water 2018, 10, 327. [CrossRef]

73. Golden Gate Weather Services. El Niño and La Niña Years and Intensities. 2021. Available online: https://ggweather.com/enso/ oni.htm (accessed on 17 May 2021). 